7-3-2018

\title{
A Series of 4- and 5-Coordinate Ni(II) Complexes: Synthesis, Characterization, Spectroscopic, and DFT Studies
}

Jack Ghannam

Loyola University Chicago

Talal Al Assil

Loyola University Chicago

Trey C. Pankratz

Grand Valley State University

Richard L. Lord

Grand Valley State University

Matthias Zeller

Purdue University Follow this and additional works at: https://ecommons.luc.edu/chemistry_facpubs

Part of the Biochemistry Commons, and the Chemistry Commons

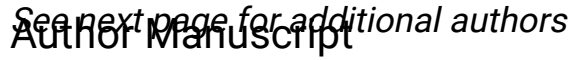

This is a pre-publication author manuscript of the final, published article.

\section{Recommended Citation}

Ghannam, Jack; Assil, Talal Al; Pankratz, Trey C.; Lord, Richard L.; Zeller, Matthias; and Lee, Wei-Tsung. A Series of 4- and 5-Coordinate Ni(II) Complexes: Synthesis, Characterization, Spectroscopic, and DFT Studies. Inorganic Chemistry, 57, 14: 8307-8316, 2018. Retrieved from Loyola eCommons, Chemistry: Faculty Publications and Other Works, http://dx.doi.org/10.1021/acs.inorgchem.8b00958

This Article is brought to you for free and open access by the Faculty Publications and Other Works by Department at Loyola eCommons. It has been accepted for inclusion in Chemistry: Faculty Publications and Other Works by an authorized administrator of Loyola eCommons. For more information, please contact ecommons@luc.edu. (c) $($ ) $\Theta$

This work is licensed under a Creative Commons Attribution-Noncommercial-No Derivative Works 3.0 License. (c) American Chemical Society 2018 


\section{Authors}

Jack Ghannam, Talal Al Assil, Trey C. Pankratz, Richard L. Lord, Matthias Zeller, and Wei-Tsung Lee 


\section{A Series of 4- and 5-Coordinate Ni(II) Complexes:}

\section{Synthesis, Characterization, Spectroscopic, and DFT}

\section{Studies}

Jack Ghannam, ${ }^{; \#}$ Talal Al Assil,${ }^{, \#}$ Trey C. Pankratz, ${ }^{+}$Richard L. Lord, ${ }^{+}$Matthias Zeller, ${ }^{\bullet}$ WeiTsung Lee $e^{* \dagger}$

${ }^{\dagger}$ Department of Chemistry and Biochemistry, Loyola University Chicago, Chicago, Illinois 60660, United States.

${ }^{*}$ Department of Chemistry, Grand Valley State University, Allendale, Michigan 49401, United States

- Department of Chemistry, Purdue University, West Lafayette, IN 47907, United States. 


\section{ABSTRACT}

A series of four- and five-coordinate $\mathrm{Ni}(\mathrm{II})$ complexes $\mathrm{Cz}^{\mathrm{tBu}}\left(\mathrm{Pyr}^{\mathrm{iPr}}\right)_{2} \mathrm{NiX}(\mathbf{1}-\mathbf{3}$ and $\mathbf{1} \cdot \mathrm{THF}-\mathbf{3} \cdot \mathrm{THF})$, where $\mathrm{X}=\mathrm{Cl}, \mathrm{Br}$, and $\mathrm{I}$, were synthesized and fully characterized by NMR and UV-Vis spectroscopy, X-ray crystallography, cyclic voltammetry, and density functional theory calculations. The solid-state structures of $\mathbf{1} \mathbf{- 3}$ reveal rare examples of seesaw Ni(II) complexes. In solution 1-3 bind reversibly to a THF molecule to form five-coordinate adducts. The electronic transitions in the visible region $(630-680 \mathrm{~nm})$, attributed to LMCT bands, for $\mathbf{1} \rightarrow \mathbf{3}$ exhibit a bathochromic shift. The thermochromic tendency of the five-coordinate complexes implies the loss of THF coordination at elevated temperatures. Finally, the electronic properties of all Ni(II) complexes were studied by time-dependent density functional theory calculations to characterize the nature of the excited states.

\section{Introduction}

Nickel complexes with NNN pincer-type ligands have been gaining increased interest in recent years, particularly in the fields of catalytic bond activation ${ }^{1-8}$ and polymerization. ${ }^{9-10}$ One of the unique features of pincer ligands is the meridional orientation that they enforce, which results in a dominantly square planar configuration for these four-coordinate $\mathrm{Ni}(\mathrm{II})$ complexes. ${ }^{1-20}$

Tuning ancillary ligands in metal complexes can govern their geometric preferences. For fourcoordinate $\mathrm{Ni}(\mathrm{II})$ centers, tetrahedral or square planar geometries are most common and well understood. $^{21}$ For example, sterically, Ni(II) complexes with bulkier ligands tend to form tetrahedral $(S=1)$ structures whereas the square planar $(S=0)$ arrangement is preferred with less sterically demanding ligands; electronically, when coordinating to weak field ligands, the tetrahedral geometry is favored while a square planar geometry is often observed in $\mathrm{Ni}(\mathrm{II})$ 
complexes bearing strong field ligands. ${ }^{22}$ Indeed, the molecular geometry and electronic configuration of metal complexes are interdependent, and they dictate the chemical reactivity of the metal complexes. In general, square planar complexes tend to be more kinetically inert than tetrahedral ones due to the greater ligand field stabilization energy in the square planar arrangement caused by the substantial electronic stabilization of the four, doubly-occupied, orbitals relative to the empty, antibonding $d x^{2}-y^{2}$ orbital. In this line, we became interested in the design, synthesis, and characterization of unusual $\mathrm{Ni}(\mathrm{II})$ complexes where the supporting ligands are used to force the metal center to adopt a high-energy and more reactive geometry. This may allow for the development of new types of reactivity of nickel complexes.

The seesaw $\mathrm{Ni}(\mathrm{II})$ coordination geometry in the $\mathrm{Ni}-\mathrm{SI}_{\mathrm{a}}$ state of the [NiFe]-hydrogenase active site is proposed to be a key feature for efficient $\mathrm{H}_{2}$ binding and activation. ${ }^{23}$ However, despite the discovery of such important structures, the synthetic routes to modulate the geometry at a nickel metal center remains challenging. Ideally, introduction of steric obstruction on the meridional plane of NNN pincer-based $\mathrm{Ni}(\mathrm{II})$ complexes could impel the fourth ligand to reside on the axial rather than an equatorial position. However, without considering the rigidity, simply increasing the bulkiness of flanking substituents does not necessarily yield a non-square planar geometry around the metal center. ${ }^{2} 24-28$ Consequently, complexes that possess a seesaw arrangement at the $\mathrm{Ni}(\mathrm{II})$ center are still underdeveloped with only one type of supporting ligand, tripyrrinato, reported in the literature. ${ }^{29}$ Nonetheless, low yields and a limited number of precursors have restricted the development of tripyrrin derivatives in nickel chemistry. ${ }^{29-31}$ In this work, we report the synthesis, structure, and characterization of a new family of $\mathrm{Cz}^{\mathrm{tBu}}\left(\mathrm{Pyr}^{\mathrm{iPr}}\right)_{2} \mathrm{NiX}$ complexes whose $\mathrm{Ni}(\mathrm{II})$ center adopts the seesaw geometry, together with their pentacoordinate THF adducts, $\mathrm{Cz}^{\mathrm{tBu}}\left(\mathrm{Pyr}{ }^{\mathrm{iPr}}\right)_{2} \mathrm{NiX}(\mathrm{THF})(\mathrm{X}=\mathrm{Cl}, \mathrm{Br}, \mathrm{I})($ Scheme 1$)$. 

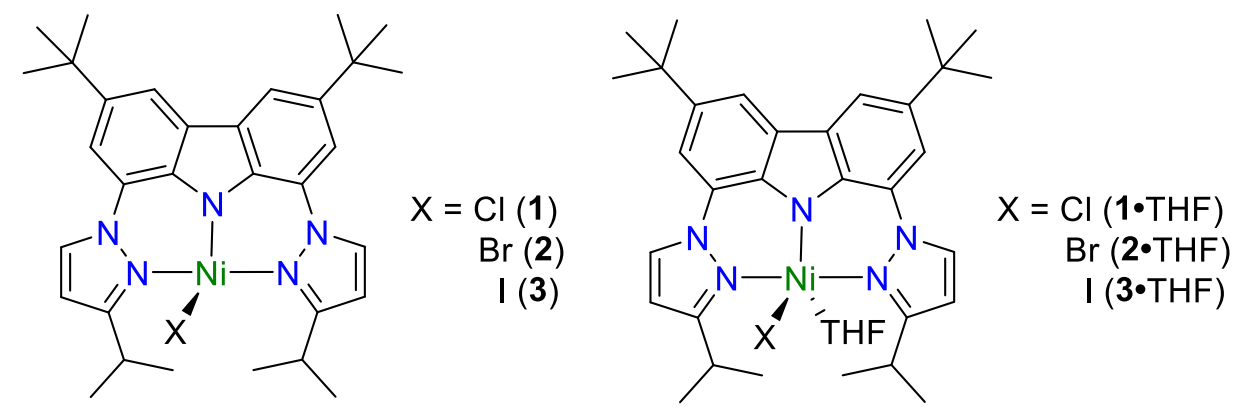

Scheme 1. Four- and five-coordinate Ni(II) complexes.

\section{Experimental Section}

Materials and Methods. All manipulations were performed under a nitrogen atmosphere using standard Schlenk techniques or in an M. Braun UNIlab Pro glovebox. Glassware was dried at 150 ${ }^{\circ} \mathrm{C}$ overnight. Diethyl ether, $n$-pentane, tetrahydrofuran, and toluene were purified using a Pure Process Technology solvent purification system. Before use, an aliquot of each solvent was tested with a drop of sodium benzophenone ketyl in THF solution. All reagents were purchased from commercial vendors and used as received. 1,8-Dibromo-3,6-di-tert-butyl-9H-carbazole $\left(\mathrm{HCz}^{\mathrm{tBu}} \mathrm{Br}_{2}\right)$ and 3-iso-propylpyrazole were prepared according to literature procedures. ${ }^{32-33}$ $\mathrm{HCz}^{\mathrm{tBu}}\left(\mathrm{Pyr}^{\mathrm{iPr}}\right)_{2}$ was prepared according to a modified literature procedure. ${ }^{34}{ }^{1} \mathrm{H}$ NMR data were recorded on Varian Inova 300 or $500 \mathrm{MHz}$ spectrometer at $22{ }^{\circ} \mathrm{C}$. Resonances in the ${ }^{1} \mathrm{H}$ NMR spectra are referenced either to residual $\mathrm{C}_{6} \mathrm{D}_{5} \mathrm{H}$ at $\delta=7.16 \mathrm{ppm}$ or $\mathrm{C}_{4} \mathrm{D}_{7} \mathrm{HO}$ at $\delta=3.58 \mathrm{ppm}$. Solution magnetic susceptibilities were determined using the Evans method. ${ }^{35} \mathrm{UV}$-Visible spectra were recorded on an Agilent Cary $8454 \mathrm{UV}$-Vis spectrophotometer equipped with a Unisoku Scientific Instruments Cryostat USP-203B for various temperature experiments. Elemental analysis was conducted by Midwest Microlab, LLC (Indianapolis, IN).

General synthesis of $\mathrm{Cz}^{t B u}\left(P y r^{i P r}\right)_{2} \mathrm{NiX}$. To a stirred solution of $\mathrm{HCz}^{t B u}\left(P y r^{i P r}\right)_{2}(500 \mathrm{mg}, 1.38$ mmol) in THF ( $3 \mathrm{~mL})$ at ambient temperature under $\mathrm{N}_{2}$ atmosphere was added a solution of lithium 
diisopropylamide (LDA) (155 mg, $1.45 \mathrm{mmol})$ in THF ( $2 \mathrm{~mL})$ for $2 \mathrm{~h}$. Solid $\mathrm{NiX}_{2}(1.45 \mathrm{mmol})(\mathrm{X}$ $=\mathrm{Cl}, \mathrm{Br}, \mathrm{I} ; \mathrm{NiBr}_{2}(\mathrm{THF})_{2}$ was used for the nickel bromide salt) was added, and the resulting slurry was stirred for $18 \mathrm{~h}$ at ambient temperature. ${ }^{36}$ Volatiles were removed under reduced pressure, and the residue was extracted with toluene and filtered through Celite. The filtrate was dried in vacuo to yield a dark green solid (complex 1-3). The corresponding THF adduct complexes were obtained by dissolving $\mathbf{1 - 3}$ in THF.

$\mathrm{Cz}^{\mathrm{tBu}}\left(\mathrm{Pyr}^{\mathrm{iPr}}\right)_{2} \mathrm{NiCl}(\mathbf{1})$. Yield: $64 \%$. Crystals suitable for X-ray diffraction were grown from a concentrated solution in toluene at ambient temperature. ${ }^{1} \mathrm{H}$ NMR (500 MHz, $\left.\mathrm{C}_{6} \mathrm{D}_{6}, \delta\right): 47.0,44.1$, $42.4,32.0$ (br), 17.8, 11.3, 7.87, 3.64. $\mu_{\text {eff }}\left(\mathrm{C}_{6} \mathrm{D}_{6}\right): 2.9 \pm 0.2 \mu_{\mathrm{B}}$. UV-vis (toluene at $\left.40{ }^{\circ} \mathrm{C}\right) \lambda_{\max }$ $\left(\varepsilon\left[\mathrm{mM}^{-1} \cdot \mathrm{cm}^{-1}\right]\right): 305(15730), 319(15470), 373(6350), 395(6370), 630(2010) 600$. Anal. Calcd for $\mathrm{C}_{32} \mathrm{H}_{40} \mathrm{ClN}_{5} \mathrm{Ni}$ : C, 65.27; H, 6.85; N, 11.89. Found: C, 64.94; H, 6.97; N, 11.59.

$C z^{t B u}\left(P y r^{i P r}\right)_{2} \mathrm{NiBr}(2)$. Yield: $88 \%$. Crystals suitable for X-ray diffraction were grown from a concentrated solution in toluene at ambient temperature. ${ }^{1} \mathrm{H}$ NMR $\left(500 \mathrm{MHz}, \mathrm{C}_{6} \mathrm{D}_{6}, \delta\right): 46.8,42.8$, 27.0 (br), 18.6, 9.13, 8.49, 3.61. $\mu_{\text {eff }}\left(\mathrm{C}_{6} \mathrm{D}_{6}\right): 3.0 \pm 0.3 \mu_{\mathrm{B}}$. UV-vis (toluene at $\left.40{ }^{\circ} \mathrm{C}\right) \lambda_{\max }\left(\varepsilon\left[\mathrm{mM}^{-}\right.\right.$ $\left.\left.{ }^{1} \cdot \mathrm{cm}^{-1}\right]\right): 320(17010), 396(7840), 651(2590)$. Anal. Calcd for $\mathrm{C}_{32} \mathrm{H}_{40} \mathrm{Br}_{2} \mathrm{~N}_{5} \mathrm{Ni} \cdot 0.5\left(\mathrm{C}_{7} \mathrm{H}_{8}\right): \mathrm{C}, 62.76$; H, 6.53; N, 10.31. Found: C, 62.90; H, 6.64; N, 10.08 .

$C z^{t B u}\left(P y r^{i P r}\right)_{2} N i I$ (3). Yield: $91 \%$. Crystals suitable for X-ray diffraction were grown from a concentrated solution in toluene at ambient temperature. ${ }^{1} \mathrm{H}$ NMR $\left(500 \mathrm{MHz}, \mathrm{C}_{6} \mathrm{D}_{6}, \delta\right): 46.1,42.4$, 40.9, 18.8, 16.0 (br), 9.93 (br), 5.37 (br), 3.37. $\mu_{\text {eff }}\left(\mathrm{C}_{6} \mathrm{D}_{6}\right): 2.9 \pm 0.3 \mu_{\mathrm{B}}$. UV-vis (toluene at $40{ }^{\circ} \mathrm{C}$ ) $\lambda_{\max } \quad\left(\varepsilon\left[\mathrm{mM}^{-1} \cdot \mathrm{cm}^{-1}\right]\right): \quad 321(15410), \quad 399(7200), \quad 680(2410) . \quad$ Anal. Calcd for $\mathrm{C}_{32} \mathrm{H}_{40} \mathrm{I}_{2} \mathrm{~N}_{5} \mathrm{Ni} \cdot 0.5\left(\mathrm{C}_{7} \mathrm{H}_{8}\right):$ C, 58.70; H, 6.11; N, 9.64. Found: $\mathrm{C}, 58.71 ; \mathrm{H}, 6.16 ; \mathrm{N}, 9.64$. $\mathrm{Cz}^{\mathrm{tBu}}\left(\mathrm{Pyr}^{\mathrm{iPr}}\right)_{2} \mathrm{NiCl(THF)}(\boldsymbol{I} \cdot \mathrm{THF})$. Crystals suitable for $\mathrm{X}$-ray diffraction were grown by slow diffusion of $n$-pentane into a THF solution at ambient temperature. ${ }^{1} \mathrm{H}$ NMR $\left(500 \mathrm{MHz}\right.$, THF- $d_{8}$, 
$\delta): 56.3,52.3,37.6,15.8$ (br), 15.1, 7.20, 2.67. $\mu_{\text {eff }}\left(\mathrm{THF}-d_{8}\right): 3.0 \pm 0.2 \mu_{\mathrm{B}} . \mathrm{UV}-\mathrm{vis}\left(\mathrm{THF}\right.$ at $\left.40{ }^{\circ} \mathrm{C}\right)$ $\lambda_{\max }\left(\varepsilon\left[\mathrm{mM}^{-1} \cdot \mathrm{cm}^{-1}\right]\right): 319(14730), 403(6780), 418(\mathrm{sh})(6400), 629(900) . \mathrm{UV}-\mathrm{vis}\left(\mathrm{THF}\right.$ at $\left.-80{ }^{\circ} \mathrm{C}\right)$ $\lambda_{\max }\left(\varepsilon\left[\mathrm{mM}^{-1} \cdot \mathrm{cm}^{-1}\right]\right): 305(11370), 325(20590), 348(10420), 403(9440), 424(11680)$. Anal. Calcd for $\mathrm{C}_{36} \mathrm{H}_{48} \mathrm{ClN}_{5} \mathrm{NiO}$ : C, 65.42; H, 7.32; N, 10.60. Found: C, 65.15; H, 7.33; N, 10.61. $C z^{t B u}\left(P y r^{i P r}{ }_{2} \mathrm{NiBr}(\mathrm{THF})(\mathbf{2} \cdot \mathrm{THF})\right.$. Crystals suitable for X-ray diffraction were grown by slow diffusion of $n$-pentane into a THF solution at ambient temperature. ${ }^{37}{ }^{1} \mathrm{H}$ NMR $(500 \mathrm{MHz}$, THF$d_{8}, \delta$ ): 55.0, 52.6, 38.7, 14.9, 12.7 (br), 7.23, 2.59. $\mu_{\text {eff }}\left(\mathrm{THF}-d_{8}\right): 3.0 \pm 0.2 \mu_{\mathrm{B}}$ UV-vis (THF at 40 $\left.{ }^{\circ} \mathrm{C}\right) \lambda_{\max }\left(\varepsilon\left[\mathrm{mM}^{-1} \cdot \mathrm{cm}^{-1}\right]\right): 303(18000), 327(17360), 351(11530), 371(\mathrm{sh})(7240), 404(7930)$, 427(10470), 653(310). UV-vis (THF at $\left.-80{ }^{\circ} \mathrm{C}\right) \lambda_{\max }\left(\varepsilon\left[\mathrm{mM}^{-1} \cdot \mathrm{cm}^{-1}\right]\right): 304(20040), 327(19290)$, 351(12810), 371(8040), 404(8820), 427(11640). Anal. Calcd for $\mathrm{C}_{36} \mathrm{H}_{48} \mathrm{BrN}_{5} \mathrm{NiO}$ : C, 61.30; $\mathrm{H}$, 6.86; N, 9.93. Found: C, 61.21; H, 6.74; N, 10.01.

$C z^{t B u}\left(P y r^{i P r}\right)_{2} \mathrm{NiI}(T H F)(3 \cdot T H F)$. Crystals suitable for X-ray diffraction were grown by slow diffusion of $n$-pentane into a THF solution at ambient temperature. ${ }^{1} \mathrm{H}$ NMR $\left(500 \mathrm{MHz}, \mathrm{THF}-d_{8}\right.$, $\delta): 51.3,51.0,39.4,14.4,7.16,2.44 . \mu_{\text {eff }}\left(\mathrm{THF}-d_{8}\right): 2.8 \pm 0.3 \mu_{\mathrm{B}}$. UV-vis (THF at $\left.40{ }^{\circ} \mathrm{C}\right) \lambda_{\max }$ $\left(\varepsilon\left[\mathrm{mM}^{-1} \cdot \mathrm{cm}^{-1}\right]\right): 303(17570), 320(11950), 352(9690), 369(\mathrm{sh})(8700), 399(6030), 426(\mathrm{sh})(4970)$, 685(730). UV-vis (THF at $\left.-80{ }^{\circ} \mathrm{C}\right) \lambda_{\max }\left(\varepsilon\left[\mathrm{mM}^{-1} \cdot \mathrm{cm}^{-1}\right]\right): 303(15590), 326(14190), 353(10760)$, 371(7770), 405(7370), 427(8940). Anal. Calcd for $\mathrm{C}_{36} \mathrm{H}_{48} \mathrm{IN}_{5} \mathrm{NiO}$ : C, 57.47; H, 6.43; N, 9.31. Found: C, 57.12; H, 6.34; N, 9.20.

Electrochemistry. Cyclic voltammetry was conducted via a $\mathrm{CH}$-Instruments electrochemical analyzer (model 620E), employing a $3 \mathrm{~mm}$ glassy carbon working electrode, a silver wire pseudoreference electrode, and a platinum coiled wire counterelectrode. All measurements were performed using either THF or dichloromethane solutions, containing $1 \mathrm{mM}$ analyte and $0.1 \mathrm{M}$ 
$\mathrm{N}(\mathrm{Bu})_{4} \mathrm{PF}_{6}$ as the supporting electrolyte. The potentials were referenced to a ferrocene/ferrocenium redox couple.

Crystallography. Data for $\mathbf{2}$ were collected using a Bruker ApexII CCD diffractometer. Data for 1, 3, 1·THF, and $[\mathbf{2} \cdot \mathrm{THF}] \cdot\left[\mathrm{Cz}^{\mathrm{tBu}}\left(\mathrm{Pyr}^{\mathrm{iPr}}\right)_{2} \mathrm{NiBr}_{2}\right]\left[\mathrm{Li}(\mathrm{THF})_{4}\right]$ were measured using a Bruker Quest CMOS diffractometer. Both instruments featured sealed tube X-ray sources with graphite monochromated Mo-K $\alpha$ radiation $(\lambda=0.71073 \AA)$. A Bruker Quest CMOS diffractometer equipped with a $\mathrm{I} \mu \mathrm{S}$ microsource with a laterally graded multilayer (Goebel) mirror for monochromatization ( $\mathrm{Cu}-\mathrm{K} \alpha$ radiation, $\lambda=1.54178 \AA$ ) was used for compound 3.THF. A single crystal of each compound was mounted on a Mitegen micromesh mount using a trace of mineral oil and cooled in situ to 100 or $150 \mathrm{~K}$ for data collection. Frames were collected, reflections were indexed and processed, and the files scaled and corrected for absorption using Apex 2 or Apex $3{ }^{38}$ For all structures, the intensity data were corrected for absorption using multi-scan techniques (SADABS or TWINABS). ${ }^{39}$ The space groups were assigned and the structures were solved by direct methods using XPREP within the SHELXTL suite of programs and refined by full matrix least squares against $F^{2}$ with all reflections using Shelx12014, 2016 or 2018 using the graphical interface Shelxle. ${ }^{40-42}$ If not specified otherwise, $\mathrm{H}$ atoms attached to carbon and nitrogen atoms and hydroxyl hydrogens were positioned geometrically and constrained to ride on their parent atoms, with carbon hydrogen bond distances of $0.95 \AA$ for alkene and aromatic $\mathrm{C}-\mathrm{H}$, and 0.99 and $0.98 \AA$ for aliphatic $\mathrm{CH}_{2}$ and $\mathrm{CH}_{3}$ moieties, respectively. Methyl $\mathrm{H}$ atoms were allowed to rotate but not to tip to best fit the experimental electron density. $\mathrm{U}_{\text {iso }}(\mathrm{H})$ values were set to a multiple of $\mathrm{U}_{\text {eq }}(\mathrm{C})$ with 1.5 for $\mathrm{CH}_{3}$ and 1.2 for $\mathrm{CH}_{2}$ and $\mathrm{CH}$ units, respectively. Additional experimental details for all structures are given in the SI. Structures, in CIF format, have been deposited with the Cambridge Crystallographic Data Centre, CCDC 1834881-1834886. These data can be 
obtained free of charge from The Cambridge Crystallographic Data Centre via $\underline{\text { www.ccdc.cam.ac.uk/data_request/cif. }}$

Computational details. Molecular structures were geometry optimized using density functional theory (DFT) at the B3LYP/6-311G(d)/SDD level of theory, ${ }^{43-47}$ where Ni and the halide were represented with SDD and all other elements with 6-311G(d), as implemented in Gaussian 09. ${ }^{48}$ Optimized structures were confirmed to be minima by analyzing harmonic frequencies. ${ }^{49}$ The wavefunction for each triplet state was confirmed to be stable. ${ }^{50-51}$ Single point energy refinements at these optimized structures were evaluated at the B3LYP/def2TZVP and OPBE/def2TZVP levels of theory $\left(\mathrm{G}_{\mathrm{TZ}} \approx \mathrm{G}_{\mathrm{DZ}}-\mathrm{E}_{\mathrm{DZ}}+\mathrm{E}_{\mathrm{TZ}}\right)$. The effects of solvation were not included during geometry optimization but were included when simulating the UV-Vis spectra using the SMD implicit solvation model for toluene or THF. ${ }^{52}$ Time-dependent DFT (TD-DFT) was employed to simulate these spectra at the B3LYP/def2TZVP level of theory (see Figure S9 for the poor performance of a long-range corrected functional). ${ }^{53-55} 50$ excited states were simulated for each molecule and the resulting oscillators were each fit with a Gaussian with a half-width at half-maximum of $0.15 \mathrm{eV}$ using GaussView to represent the absorption spectra. ${ }^{56}$ Optimized geometries were visualized with CYLview. ${ }^{57}$

\section{Results and Discussion}

Syntheses. The synthesis of the ligand was adapted from one reported for a similar compound, $\mathrm{HCz}^{\mathrm{Me}}\left(\mathrm{Pyr}^{\mathrm{iPr}}\right)_{2}{ }^{58}$ Reaction yields and purity were improved by increasing the amount of base and pyrazole used. ${ }^{34}$ Most importantly, no column chromatography is required for purification. A general synthetic route towards the $\mathrm{Ni}(\mathrm{II})$ complexes is shown in Scheme 1. Dark green $\mathrm{Cz}^{\mathrm{tBu}}\left(\mathrm{Pyr}^{\mathrm{iPr}}\right)_{2} \mathrm{NiX}(\mathrm{X}=\mathrm{Cl}, \mathrm{Br}$, and $\mathrm{I})$ complexes $\mathbf{1}-\mathbf{3}$ were prepared by the addition of $\mathrm{NiX}_{2}$ to in 
situ prepared $\mathrm{Cz}^{\mathrm{tBu}}\left(\mathrm{Pyr}^{\mathrm{iPr}}\right)_{2} \mathrm{Li}$ (Scheme 2). The complexes were isolated in high yields and were fully characterized by NMR and UV-Vis spectroscopy, elemental analysis, and single-crystal Xray crystallography. 1-3 did not show any significant sign of decomposition upon standing in benzene on the benchtop for several days. In $\mathrm{C}_{6} \mathrm{D}_{6}$ solution of complexes $\mathbf{1 - 3}$, one set of paramagnetic shifts was observed, indicating $C_{\mathrm{s}}$ symmetry with the mirror plane passing through the carbazole nitrogen, the Ni center, and the halide. The paramagnetic ${ }^{1} \mathrm{H}$ NMR spectra suggest a non-square planar coordination geometry around the $\mathrm{Ni}(\mathrm{II})$ center. Magnetic data for $\mathbf{1 - 3}$ are consistent with a high-spin nickel system. Values obtained using the method of Evans are $\mu_{\text {eff }}=$ 2.9(2), 3.0(3), and 2.9(3) $\mu_{\mathrm{B}}$, respectively. Note that remaining half equiv of toluene cannot be removed by high vacuum overnight according to the results of elemental analysis for 1-3.

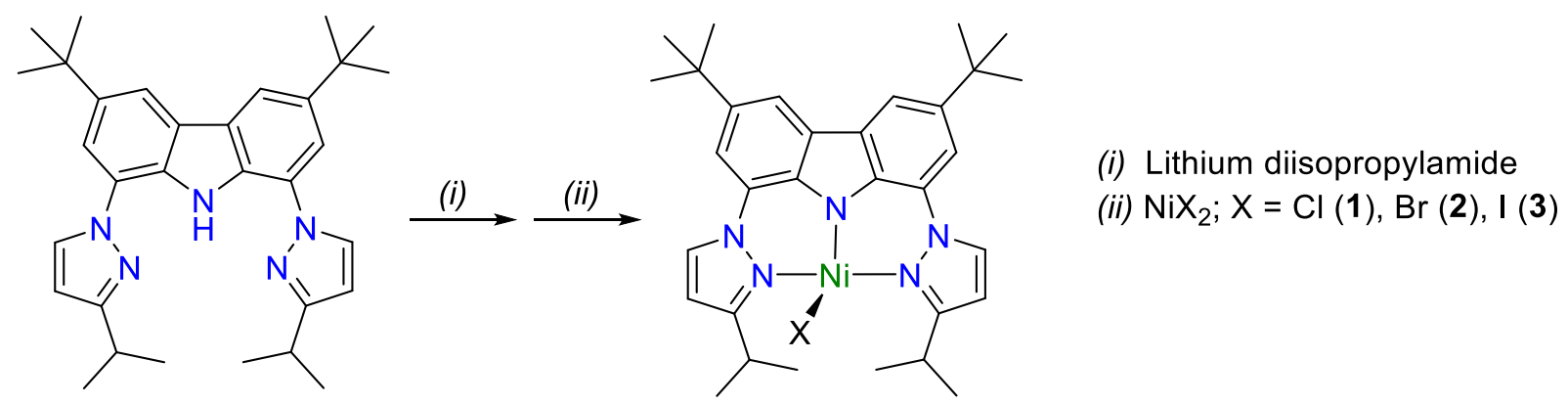

Scheme 2. Synthetic route of four-coordinate Ni(II) complexes.

Crystal structures of 1-3. Dark green crystals of 1-3 were obtained from a concentrated solution in toluene at ambient temperature. The ORTEP diagrams of $\mathbf{1 - 3}$ are given in Figure 1 and selected bond lengths and angles are summarized in Table 1 and Table S1. Each Ni(II) atom is coordinated by one carbazolide-nitrogen $\left(\mathrm{N}_{\mathrm{cz}}\right)$ and two pyrazole-nitrogen atoms $\left(\mathrm{N}_{\mathrm{pyr}}\right)$ of $\mathrm{Cz}^{\mathrm{tBu}}\left(\mathrm{Pyr}^{\mathrm{iPr}}\right)_{2}^{-}$in a meridional arrangement, and one halide atom. Such a distorted tetrahedral geometry is better described as an unusual seesaw geometry $\left(\tau_{4}=0.52,0.53\right.$, and 0.57 , respectively) $,{ }^{59}, 60$ having a $C_{\mathrm{S}}$ symmetry. The average $\mathrm{Ni}-\mathrm{N}$ bond lengths decrease from 2.002 (1) to 1.990 (2) to 1.981 (3) 
$\AA$, respectively. When comparing both types of nickel-nitrogen distances in $\mathbf{1 - 3}$, it becomes evident that the carbazolide (Ni1- $\mathrm{N}_{\mathrm{cz}}$ ) exhibits a significantly shorter bond length (ca. $\left.0.2 \AA\right)$ with respect to the corresponding pyrazole moieties $\left(\mathrm{Ni1}-\mathrm{N}_{\mathrm{pyr}}\right)$. This suggests that the negative charge is localized on the carbazole, as opposed to other types of nickel complexes bearing monoanionic NNN pincer ligands where all Ni-N distances are comparable because of charge delocalization throughout the entire molecule (Scheme 3). ${ }^{1-3,5,24,26-27,29,61}$

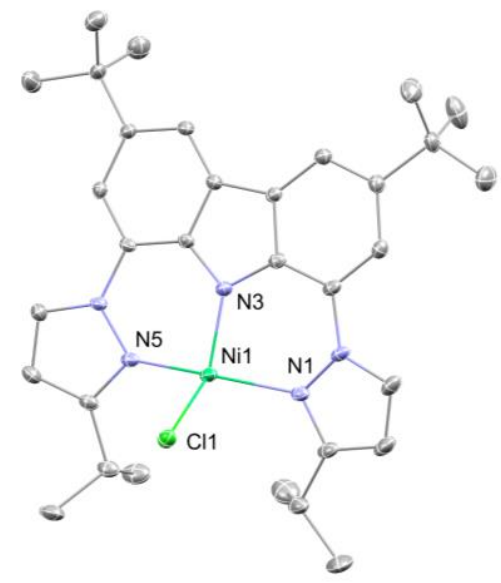

1

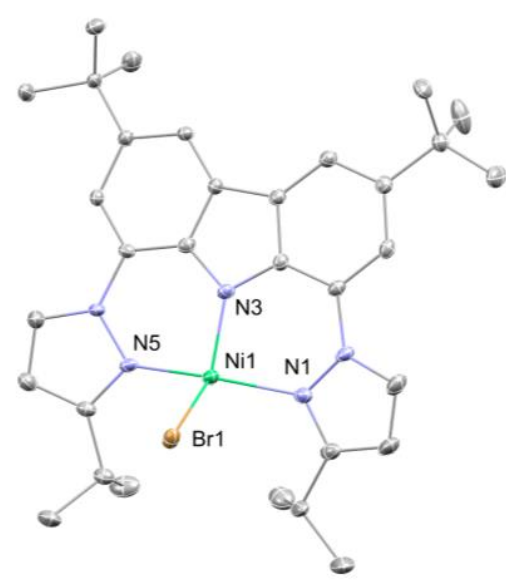

2

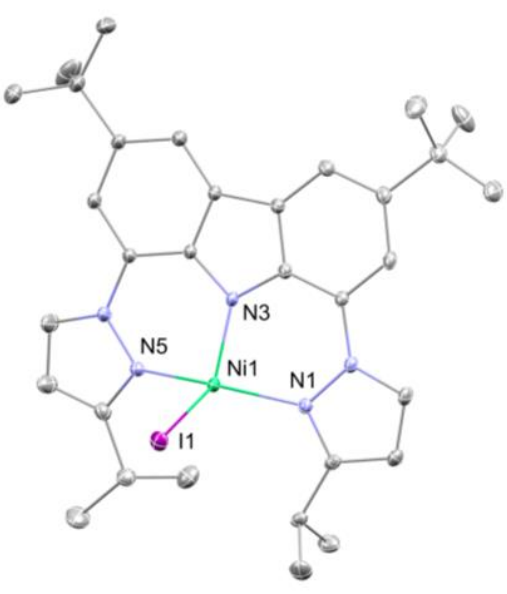

3

Figure 1. X-ray crystal structures of $\mathbf{1}$ (left), $\mathbf{2}$ (middle), and $\mathbf{3}$ (right). Thermal ellipsoids shown at $50 \%$ probability, hydrogen atoms and solvate molecules (toluene, pentane) omitted for clarity. Color key: turquoise $=\mathrm{Ni}$, blue $=\mathrm{N}$, gray $=\mathrm{C}$, green $=\mathrm{Cl}$, brown $=\mathrm{Br}$, violet $=\mathrm{I}$.

Table 1. Selected Bond Distances $(\AA)$ and Angles $\left({ }^{\circ}\right)$ for 1, 2, and 3. ${ }^{\mathrm{a}}$

\begin{tabular}{llll}
\hline & $\mathbf{1}(\mathrm{X}=\mathrm{Cl})$ & $\mathbf{2}(\mathrm{X}=\mathrm{Br})$ & $\mathbf{3}(\mathrm{X}=\mathrm{I})$ \\
\hline Ni1-N3 & $1.879(2)$ & $1.874(2)$ & $1.871(1)$ \\
Ni1-N5 & $2.071(2)$ & $2.055(2)$ & $2.044(1)$ \\
Ni1-N1 & $2.056(2)$ & $2.041(2)$ & $2.029(1)$ \\
Ni1-X1 & $2.2423(7)$ & $2.3807(5)$ & $2.5658(4)$ \\
N3-Ni1-N5 & $91.1(1)$ & $91.5(1)$ & $89.98(5)$
\end{tabular}




$$
\begin{array}{llll}
\text { N1-Ni1-N3 } & 90.6(1) & 90.9(1) & 91.01(5) \\
\text { N1-Ni1-N5 } & 157.43(9) & 158.16(9) & 154.12(5) \\
\text { N3-Ni1-X1 } & 129.44(7) & 127.42(7) & 124.25(4)
\end{array}
$$

a Numbers in parentheses are standard uncertainties in the last significant figures. Atoms are labeled as indicated in Figure 1.<smiles>[R20]c1ccccc1Nc1cccc2cccnc12</smiles><smiles>[R20]Nc1ccccc1Nc1ccccc1N[R2]</smiles><smiles>[R]C1COC(/C=C2/CC/C(=C\C3=NC([R])CO3)N2)=N1</smiles><smiles>[R]C1COC(c2ccccc2Nc2ccccc2C2=NC([R])CO2)=N1</smiles><smiles>[R]C1COC(C=c2[nH]c(=CC3=NC([R])CO3)c3ccccc23)=N1</smiles><smiles>CCC1=C(CC)C(C)=NC1=Cc1[nH]c(C=C2N=C(C)C(CC)=C2CC)c(CC)c1CC</smiles>

Scheme 3. Monoanionic NNN pincer ligands with delocalized $\pi$ system.

The Ni1-Cl1 distance in 1 is 2.2423(7) $\AA$, which is 0.138 and $0.185 \AA$, respectively, shorter than the corresponding Ni1-Br1 and Ni1-I1 distances, and is similar to the differences observed in the $\mathrm{Tp}^{\mathrm{Ph}} \mathrm{NiX}$ series $(\mathrm{X}=\mathrm{Cl}, \mathrm{Br}, \mathrm{I}),{ }^{62}$ and consistent with the differences in covalent radii for chlorine and bromine $(0.12 \AA)$, and for bromine and iodine $(0.17 \AA) .{ }^{63}$ Interestingly, a search of the CSD (November, 2017 update) revealed that the nickel halide distances in 1-3 are slightly longer $(\sim 0.1$ Å) that those of other structurally characterized NNN pincer and tripodal Ni(II) complexes. We attribute this to the steric obstruction of the two $i$ Pr groups. The steric repulsion between the halide and $i$ Pr groups can also be observed in the N3-Ni1-X1 angles, $(\theta)$ (Figure 2), which decrease with increasing radius of the halide atoms. 


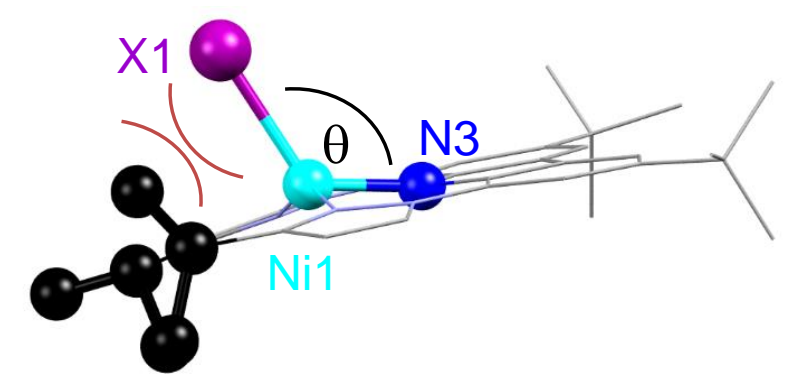

Figure 2. Illustration of $\angle \mathrm{N} 3-\mathrm{Ni1}-\mathrm{X} 1(\theta)$ due to the steic hindrance of $i \mathrm{Pr}$ groups and halides. Color key: turquoise $=\mathrm{Ni}$, blue $=\mathrm{N} 3$, black $=i \operatorname{Pr}$ groups, violet $=\mathrm{X} 1(\mathrm{X}=$ halide $)$.

Five-coordinate Ni(II) complexes. Upon dissolving the complexes in THF, a color change was observed, suggesting the coordination of solvent molecule(s) to the Ni center. The significantly different paramagnetic shifts observed in THF- $d_{8}$, compared to spectra obtained in noncoordinating solvents, imply that the formation of five- or six-coordinate high-spin Ni(II) complexes is possible. However, octahedral Ni(II) is unlikely because of the presence of two bulky $i \operatorname{Pr}$ groups located trans to the carbazole nitrogen. Reversible solvation is evident from the observation that the dark green four-coordinate complexes turns yellow-green in THF. When dried, the solid remains yellow-green with no sign of loss of THF even upon prolonged evacuation as verified by the results of elemental analysis. However, the yellow-green solid instantaneously turns dark green when dissolving in an excess of a non-coordinating solvent, such as toluene. Interestingly, upon cooling of the solutions, toluene solutions remain dark green, while an apparent color change from yellow-green to dark brown is noticed for THF solutions.

Crystal structures of five-coordinate Ni(II) complexes. Crystals of the five-coordinate Ni(II) complexes were obtained from concentrated THF solutions. The molecular structures of $\mathbf{1} \cdot \mathrm{THF}$, 2.THF, and 3.THF are shown in Figures S1, S2 and 3, and the crystallographic data are summarized in Table 2 and Table S2. Each Ni(II) center is coordinated by three nitrogens, one halide, and one oxygen atom in a distorted square pyramidal fashion $\left(\tau_{5}=0.34,0.30\right.$, and 0.12 , 
respectively) ${ }^{64}$ The additional ligation results in several observations that are different from 1-3. First, the average $\mathrm{Ni}-\mathrm{N}$ bond lengths of the THF-bonded complexes are almost identical (ca. 2.00 $\AA$ ), whereas an elongation of $c a .0 .2 \AA$ was found for the $\mathrm{Ni}-\mathrm{X}$ distances. Second, N3-Ni1-X1 angles decrease by $c a .20^{\circ}$. These results may be attributed to a diminished out-of-plane movement (0.439 (3) and $0.081(3 \cdot \mathrm{THF}) \AA)$ of the $\mathrm{Ni}(\mathrm{II})$ ion in the five-coordinate complexes, where the basal plane is defined by the three coordinated nitrogen atoms N1, N3 and N5.

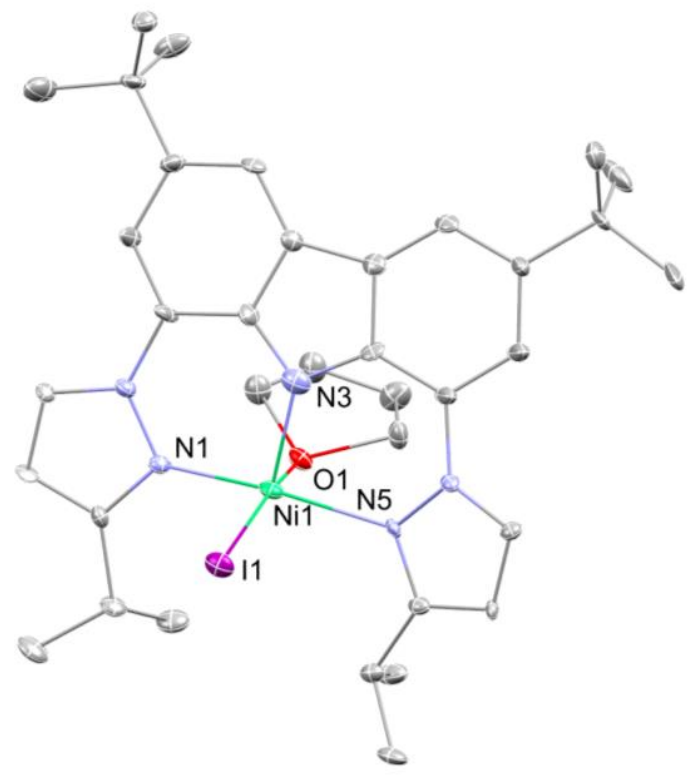

Figure 3. X-ray crystal structure of 3.THF. Thermal ellipsoids shown at $50 \%$ probability, hydrogen atoms and disorder (of isopropyl groups and the THF molecule) are omitted for clarity. Color key: turquoise $=\mathrm{Ni}$, blue $=\mathrm{N}$, gray $=\mathrm{C}$, red $=\mathrm{O}$, violet $=\mathrm{I}$.

Table 2. Selected Bond Distances $(\AA)$ and Angles $\left({ }^{\circ}\right)$ for 1-THF, 2.THF, and 3.THF. ${ }^{a}$

\begin{tabular}{llll}
\hline & $\mathbf{1} \cdot \mathrm{THF}(\mathrm{X}=\mathrm{Cl})^{\mathrm{b}}$ & $\mathbf{2} \cdot \mathrm{THF}(\mathrm{X}=\mathrm{Br})$ & $\mathbf{3 \cdot T H F}(\mathrm{X}=\mathrm{I})$ \\
\hline Ni1-N3 & $1.90(1)$ & $1.906(4)$ & $1.907(6)$ \\
Ni1-N5 & $2.04(1)$ & $2.044(3)$ & $2.12(2)$
\end{tabular}




$\begin{array}{llll}\text { Ni1-N1 } & 2.05(1) & 2.045(8) & 1.96(2) \\ \text { Ni1-X1 } & 2.319(5) & 2.4355(7) & 2.718(1) \\ \text { Ni1-O1 } & 2.23(3) & 2.26(2) & 2.22(3) \\ & & & \\ \text { N3-Ni1-N5 } & 91.8(7) & 90.8(1) & 91.7(9) \\ \text { N1-Ni1-N3 } & 92.0(5) & 91.5(1) & 94.6(9) \\ \text { N3-Ni1-O1 } & 94.3(5) & 95.0(4) & 91.6(9) \\ \text { N1-Ni1-N5 } & 175.3(5) & 171.5(1) & 172(1) \\ \text { N3-Ni1-X1 } & 109.9(4) & 111.4(1) & 103.7(2) \\ \text { X1-Ni1-O1 } & 155.8(4) & 153.6(4) & 164.3(8)\end{array}$

${ }^{a}$ Numbers in parentheses are standard uncertainties in the last significant figures. Atoms are labeled as indicated in Figure 3, S1, and S2. ${ }^{b}$ Values taken in average of the asymmetric unit.

Electrochemistry. The electrochemistry of all six Ni(II) complexes was examined using cyclic voltammetry. Cyclic voltammograms of $\mathbf{1}-\mathbf{3}$ do not provide any informative results. Fivecoordinate $\mathrm{Ni}(\mathrm{II})$ complexes with bound $\mathrm{THF}$, on the other hand, exhibit voltammograms that show a one quasi-reversible diffusion-controlled process (shown in Figure S3 for 3.THF in THF), which we attributed to a $\mathrm{Ni}^{\mathrm{II} / \mathrm{I}}$ event. The quasi-reversibility could be due to the slow rate of THF dissociation in the reduced state. There is a slight anodic shift from $-1.53 \mathrm{~V}(1 \cdot \mathrm{THF})$ to $-1.42 \mathrm{~V}$ (2.THF), and further to $-1.33 \mathrm{~V}(\mathbf{3} \cdot \mathrm{THF})$ (Figure S4) with a linear correlation of the potential with the Lewis basicity of the halides, as expressed by the ligand constant parameter $P_{\mathrm{L}}{ }^{65} \mathbf{1} \cdot \mathrm{THF}$ is the most difficult to reduce due to both greater Lewis basicity and better $p(\mathrm{X})-d(\mathrm{Ni})$ orbital overlap of the chloride anion. In addition, the reduction potential of $\mathbf{3} \cdot$ THF is significantly more positive than that of $\mathbf{1} \cdot \mathrm{THF}$ and $\mathbf{2} \cdot \mathrm{THF}$, as implied by the more significant bending $(\angle \mathrm{N} 3-\mathrm{Ni} 1-\mathrm{X} 1)$ in $\mathbf{3} \cdot \mathrm{THF}$ which mitigates the orbital overlap. 
Electronic spectra. Qualitatively similar electronic absorption spectra were recorded for all complexes, and these spectra are consistent with the trend described in the spectrochemical series, with general ligand field-transition energy decreasing in the halide series when moving down the group (Figure 4 and Figure S5). For example, the absorption wavelength of the lowest energy bands are in the visible region, and are red-shifted from $\mathbf{1}(630 \mathrm{~nm})$ to $\mathbf{2}(651 \mathrm{~nm})$ to $\mathbf{3}(680 \mathrm{~nm})$. These bands are characteristic of high-spin distorted tetrahedral nickel(II) complexes and are thus assigned to electronic transitions which are either $d-d\left({ }^{3} T_{1} \rightarrow{ }^{3} T_{2}\right)$ or LMCT in character.
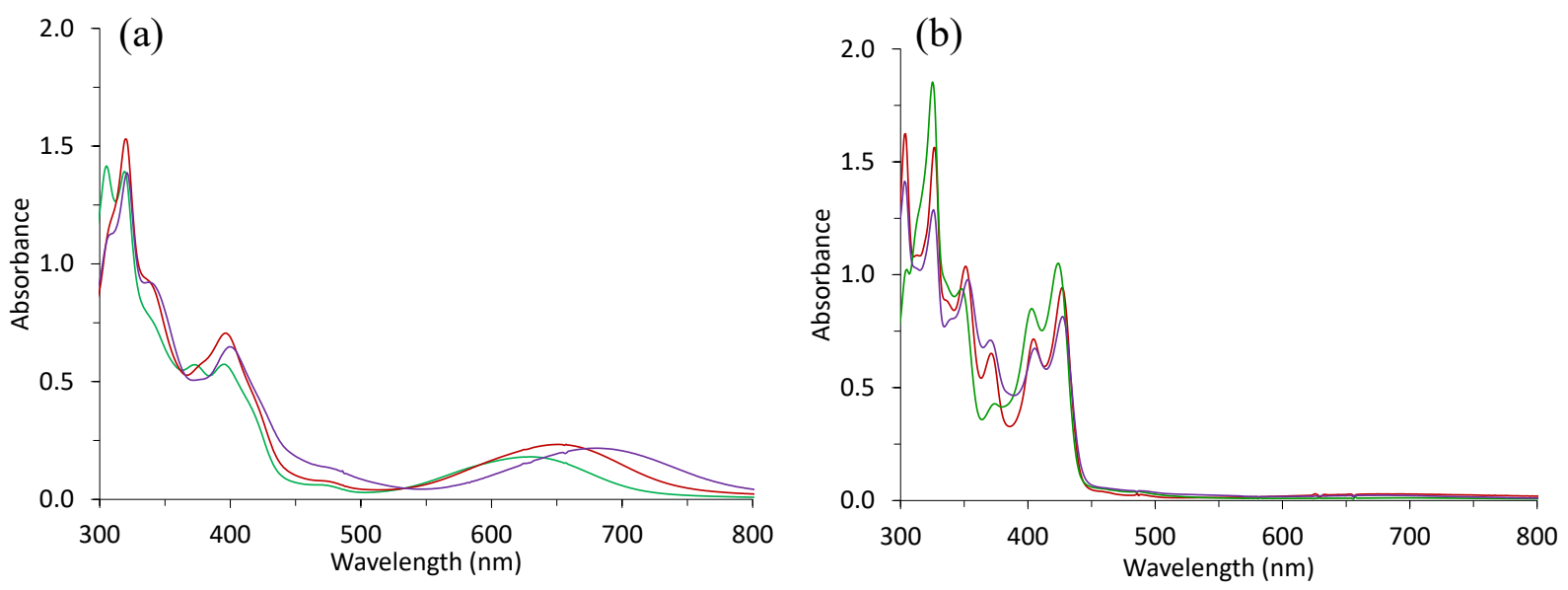

Figure 4. Electronic absorption spectra of (a) $0.09 \mathrm{mM}$ of $\mathbf{1}(-), \mathbf{2 ( - )}$, and $\mathbf{3}(-)$ in toluene at $40{ }^{\circ} \mathrm{C}$; and (b) $0.09 \mathrm{mM}$ of $\mathbf{1} \cdot \mathrm{THF}(-), \mathbf{2} \cdot \mathrm{THF}(-)$, and $\mathbf{3} \cdot \mathrm{THF}(-)$ in THF at $-80{ }^{\circ} \mathrm{C}$.

The color change behavior prompted us to conduct solvent- and temperature-dependent studies. At $40{ }^{\circ} \mathrm{C}$, the four-coordinate complexes exhibit stronger transition bands than those of the fivecoordinate counterparts. Upon cooling to $-80{ }^{\circ} \mathrm{C}$, the change in relative intensities of these bands is insignificant in toluene solutions, whereas drastically different spectra are observed in THF (Figure S6). Figure 5 shows temperature-dependent electronic absorption spectra of 2.THF from 40 to $-80{ }^{\circ} \mathrm{C}$. The $\mathrm{UV}-\mathrm{V}$ is spectral change is accompanied by one set of isosbestic points, and is 
reversible during repeated heating and cooling cycles. The small transition bands ( $\sim 600$ to 700 $\mathrm{nm}$ ) observed in THF solutions are probably related to the presence of a four-coordinate complex. As the temperature is increased, the concentration of the four-coordinate complex increases relative to that of five-coordinate species.

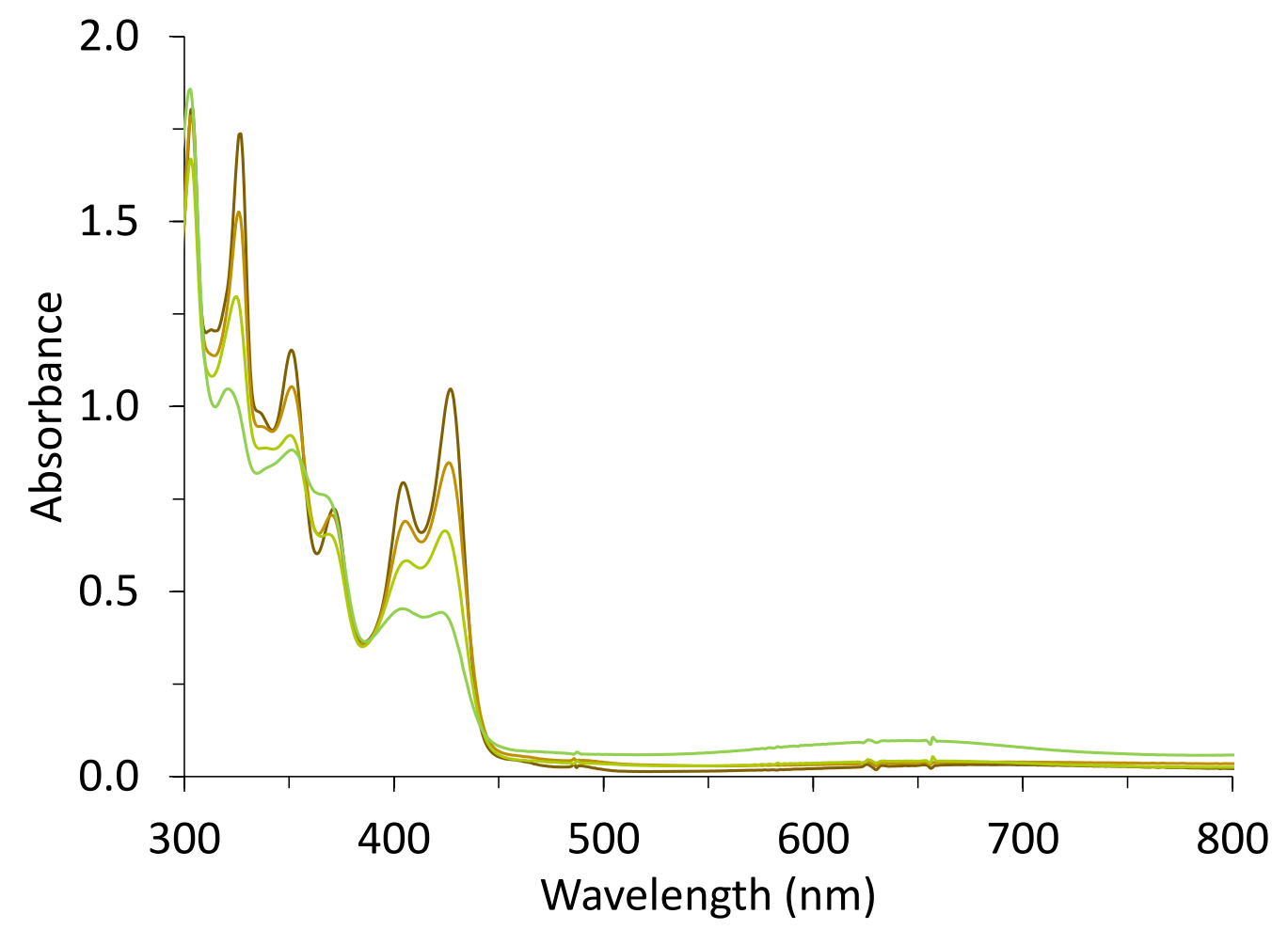

Figure 5. Temperature-dependent electronic absorption spectra of $0.09 \mathrm{mM}$ of 2.THF. $40{ }^{\circ} \mathrm{C}(-)$, $0{ }^{\circ} \mathrm{C}(-),-40{ }^{\circ} \mathrm{C}(-),-80{ }^{\circ} \mathrm{C}(-)$.

DFT Calculations. 1-3 and the mono THF adducts were optimized at the B3LYP/SDD/6$311 \mathrm{G}(\mathrm{d})$ level of theory as a triplet, where Ni and the halide were represented with the SDD basis set and all other atoms with $6-311 \mathrm{G}(\mathrm{d})$. One small chemical simplification of the ligand was introduced; the $t \mathrm{Bu}$ groups on the backbone were substituted by hydrogens. The metal-ligand bond lengths and angles agree well with the crystallographic values (Tables S4 and S5), suggesting that the model is adequate. Calculated $d$-orbital splitting diagrams for $\mathbf{1}$ and $\mathbf{1}$.THF are shown in Figure 
6. Two singly occupied molecular orbitals (SOMOs), $d x^{2}-y^{2}$ and $d z^{2}$, are energetically wellseparated from three low-lying doubly-occupied $d$ orbitals. As is shown in Figure 7, the HOMO (in both the $\alpha$ and $\beta$ subspaces) is best described as a ligand $\pi$ orbital for both the four- and fivecoordinate species with only a small contribution from Ni (see Figure S8 for similar plots of 2 and 3). The ligand-centered HOMO is commonly observed in donor ligands with more extended $\pi$ conjugation. ${ }^{66}$
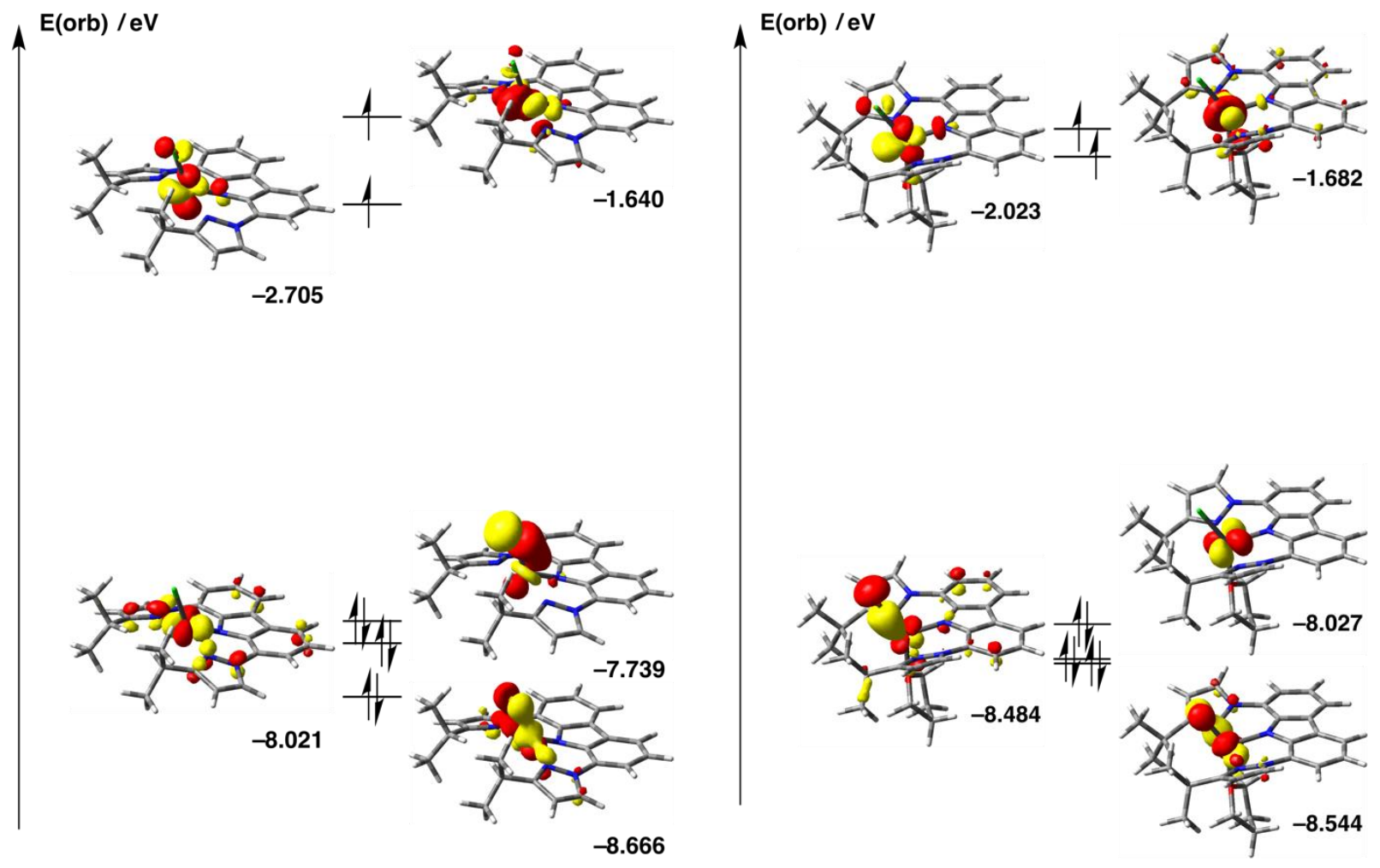

Figure 6. Quantitative $d$-orbital splitting diagrams based on the $\beta$ orbital energies with isosurface plots (iso $=0.05 \mathrm{au}$ ) for $\mathbf{1}$ (left) and $\mathbf{1} \cdot \mathrm{THF}$ (right). 

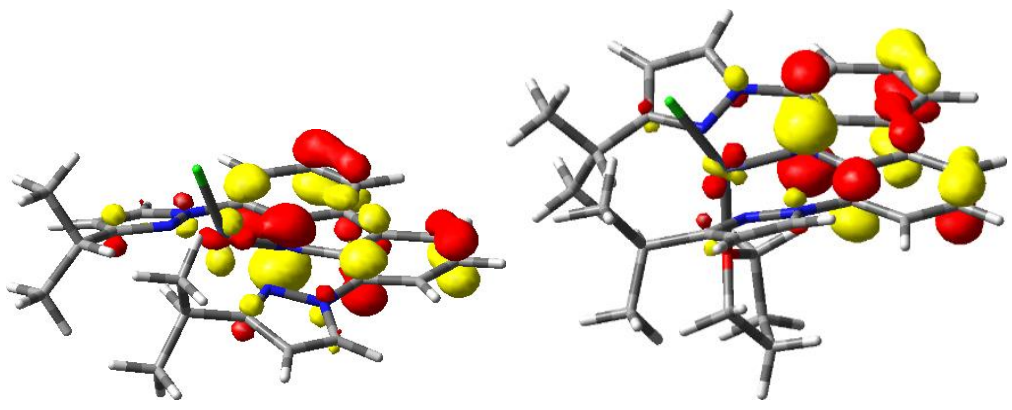

Figure 7. Isosurface plots (iso $=0.05 \mathrm{au}$ ) of the HOMO for $\mathbf{1}$ (left) and 1·THF (right).

One interesting finding in our system $v s$. the carbazole-based pincer reported by Hecht and Limberg is the short $\mathrm{Ni}-\mathrm{N}($ carbazole) bond length of 1.87-1.91 $\AA$ vs. their observed bond length of 2.032(5) $\AA .{ }^{67} \mathrm{~A}$ fundamental difference between these structures is that their bis homoleptic complex has trans carbazole Ns, potentially giving rise to a strong trans influence that elongates this $\mathrm{Ni}-\mathrm{N}$ bond length. Our complexes do not have a ligand perfectly trans to the carbazole $\mathrm{N}$ in either 1-3 or their THF adducts. To test this hypothesis, calculations were run (in addition to 1) on: (i) an analogue of $\mathbf{1}$ with ${ }^{\mathrm{i}} \operatorname{Pr}$ substituted by Me (1Me) and (ii) an analogue of $\mathbf{1}$ with ${ }^{\mathrm{i}} \operatorname{Pr}$ substituted by $\mathrm{H}(\mathbf{1} \mathbf{H})$, and (iii) an analogue of $\mathbf{1}$ where the pyrazole arms were substituted by the triazole arms of their Ni complex (1 tri). ${ }^{67}$ Each was treated as a triplet in keeping with the experimental spin state of $\mathbf{1}$. Similar to our modeling of $\mathbf{1}$, the ${ }^{\mathrm{t}} \mathrm{Bu}$ groups were omitted from the carbazole backbone of each complex (see Figure 8). First, $\mathbf{1}_{\text {tri }}$ is predicted by DFT to have a significantly shorter $\mathrm{Ni}-\mathrm{N}($ carbazole) bond length of $1.94 \AA$. This supports our hypothesis that the lengthened $\mathrm{Ni}-\mathrm{N}$ (carbazole) bond length is due to the trans influence from the other carbazole nitrogen. Second, as the steric bulk of position 3 on the pyrazole arm increases from $\mathrm{H}$ to $\mathrm{Me}$ to iPr in $\mathbf{1} \mathbf{H}, \mathbf{1} \mathrm{Me}$, and $\mathbf{1}$, respectively, the $\mathrm{N}($ carbazole $)-\mathrm{Ni}-\mathrm{Cl}$ angle becomes more acute $\left(163^{\circ}, 135^{\circ}\right.$, and $133^{\circ}$ ). As the halide is forced out of the plane the trans influence of this halide is reduced, and subsequently the $\mathrm{Ni}-\mathrm{N}$ (carbazole) bond length decreases with values of $1.928,1.920$, and $1.920 \AA$ for $\mathbf{1}_{\mathrm{H}}, \mathbf{1}_{\mathrm{Me}}$, and $\mathbf{1}$, respectively. While we focus on analogues of $\mathbf{1}$ for this analysis due to the 
system size, we anticipate these findings to be general for other halides and regardless of whether THF is coordinated.

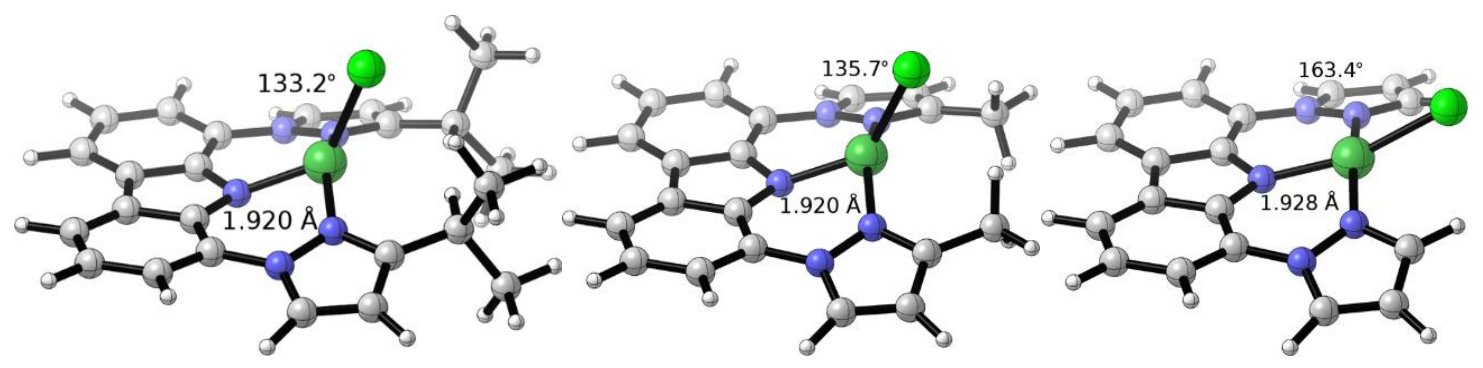

Figure 8. Optimized structures of $\mathbf{1}$ (left), $\mathbf{1}$ Me (middle), and $\mathbf{1} \mathbf{H}$ (right) with $\mathrm{Ni}-\mathrm{N}$ (carbazole) bond length and $\mathrm{N}($ carbazole $)-\mathrm{Ni}-\mathrm{Cl}$ bond angles labeled.

Because the $\mathrm{N}$ (carbazole)-Ni-X bond angle increases as the steric profile of the pyrazole substituent decreases in $\mathbf{1}$ vs. 1Me vs $\mathbf{1} \mathbf{H}$, the low-spin, singlet $\mathrm{Ni}$ (II) complex may become competitive energetically with the high-spin, triplet state. To decouple steric from electronic effects we re-optimized each of these species and $\mathbf{2 / 3}$ as closed-shell singlets, as well as hypothetical hydride (4) and cyanide (5) complexes that replace the weak-field chloride ligand with a $\sigma$-donor and $\pi$-acid, respectively. The steric profile of these two alternative ligands helps test for steric effects in these complexes. Table 3 summarizes the structural and energetic differences between these spin states. Focusing first on the structure of the triplets, $\tau_{\delta}$ is close to the ideal value for a see-saw complex for each triplet except $\mathbf{1}_{\mathbf{H}}$. Inspection of the $\mathbf{1}_{\mathbf{H}}$ triplet structure shows a short $\mathrm{Cl} \cdots \mathrm{H}$ distance of $2.72 \AA$ that suggests intramolecular hydrogen bonding. ${ }^{53,68-70}$ Combined with the fact that hydride has a structure that is closer to see-saw than $\mathbf{1}(0.47$ vs. 0.45), these observations strongly suggest that the triplet geometry is controlled by the electronic structure at the $\mathrm{Ni}$ center except when the ligand has special interactions with the pyrazole substituent. The closed-shell singlets all have smaller $\tau \delta$ values than their corresponding 
triplets, consistent with a trend toward more square-planar structures. The largest variation is seen for hydride whose singlet has a value of 0.15 . These values suggest that even sterically small ligands like cyanide (5) are effectively blocked by the pyrazole isopropyl groups, or that chloride is blocked by the much smaller methyl substituent $\left(\mathbf{1}_{\mathbf{M e}}\right)$; only singlet hydride approaches a $\tau_{\delta}$ value that is comparable to related low-spin Ni(II) pincer complexes $\left(\tau_{\delta}=0.09-0.13\right)$. Even though these singlets are more square planar, only hydride clearly favors a singlet state according to our predicted free energy differences. DFT is well-documented to be sensitive to spin-state splitting energies, so we evaluated triple-zeta energy refinements with OPBE in addition to B3LYP. ${ }^{69}$ These free energy differences suggest that $\mathbf{1} \mathbf{H}$ and $\mathbf{5}$ may also favor the singlet state.

\begin{tabular}{|c|c|c|c|c|}
\hline & \multicolumn{2}{|c|}{$\tau_{\text {。 }}$} & \multicolumn{2}{c|}{$\Delta$ G (kcal/mol) } \\
\hline Species & $\boldsymbol{S = 0}$ & $\boldsymbol{S}=\mathbf{1}$ & B3LYP & OPBE \\
\hline $\mathbf{1}$ & 0.36 & 0.45 & 10.74 & 4.86 \\
\hline $\mathbf{1}_{\text {ме }}$ & 0.36 & 0.44 & 9.20 & 3.33 \\
\hline $\mathbf{1}_{\text {н }}$ & 0.19 & 0.22 & 0.90 & -6.16 \\
\hline $\mathbf{2}$ & 0.39 & 0.47 & 12.03 & 6.23 \\
\hline $\mathbf{3}$ & 0.40 & 0.49 & 13.23 & 7.56 \\
\hline $\mathbf{4}$ & 0.15 & 0.47 & -5.98 & -13.56 \\
\hline $\mathbf{5}$ & 0.34 & 0.46 & 4.61 & -2.69 \\
\hline
\end{tabular}

Table 3. Comparison of the $\tau_{\delta}$ values for the singlet and triplet states, as well as the spin state energy difference $\left(\Delta \mathrm{G}=\mathrm{G}_{\mathrm{s}=0}-\mathrm{G}_{s=1}\right)$, for 1-5.

To aid in the interpretation of the electronic spectra, TD-DFT simulations were performed. UVVis spectra were simulated with B3LYP/def2TZVP with implicit solvation (Figure 9). When comparing the calculated spectra of the four-coordinate complexes (Figure 9a) to the experimental 
results in Figure 4a, DFT predicts the transitions within $\sim 20 \mathrm{~nm}$ of the observed experimental $\lambda_{\max }$ values (Table S3), including an experimentally observed shoulder at $\sim 340 \mathrm{~nm}$ with predicted counterparts at $\mathbf{3 2 9}, 330$, and $331 \mathrm{~nm}$ for $\mathbf{1}-\mathbf{3}$, respectively. The exception are the two bands at 373 and $395 \mathrm{~nm}$ for $\mathbf{1}$ that are not seen for the other two halides; DFT predicts a single peak at 378 $\mathrm{nm}$. The experimental trend for the wavelength of this lowest energy peak having to be $\mathbf{1}<\mathbf{2}<\mathbf{3}$ is reproduced, whereas the higher energy peaks are effectively at the same position. To better understand why this lowest energy transition is sensitive to the halide but the higher energy ones are not, the nature of these transitions and donor and acceptor orbitals for each transition were analyzed and are shown in the Supporting Information (Table S6-S8). The lowest energy transition is best described as an LMCT band with the ligand $\pi$-orbital having significant character on the carbazolide nitrogen (N3) donating into the singly occupied $d z^{2}$-orbital on the Ni that has some antibonding character due to the non-planarity of the halide in these species. The higher energy and more intense transitions are various $\pi \rightarrow \pi^{*}$ transitions in the ligand backbone, consistent with the relatively unchanged absorption energies as a function of the halide.
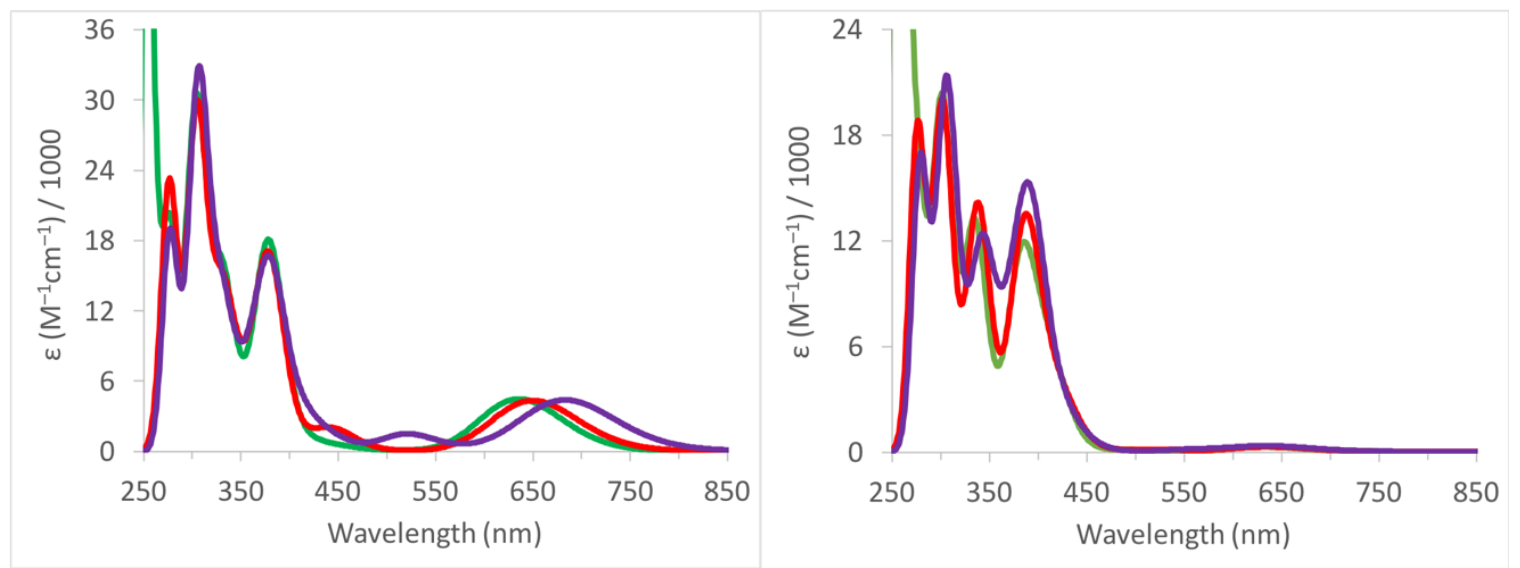

Figure 9. Simulated UV-Vis spectra for $\mathbf{1}(-), \mathbf{2}(-)$, and $\mathbf{3}(-)$ in left panel and 1·THF (-), 2.THF $(-)$, and 1.THF (-) in right panel. Individual oscillators were fit with Gaussians with a hwhm of $0.15 \mathrm{eV}$. 
Next, the spectra of the five-coordinate species (Figure 9b) were investigated and compared to the experimental spectra (Figure 4b). Based on the interpretation of the four-coordinate species, the observed transitions should all be ligand $\pi \rightarrow \pi^{*}$ transitions since they are relatively insensitive to the halide. An analysis of the donor and acceptor orbitals for these excited states (Table S9-S11) confirms this. Moreover, we can understand the absence of the low-energy transition; the $d z^{2}$ orbital is shifted higher in energy due to the increased antibonding character when THF donates into this orbital, and this transition mixes with the higher energy/intensity ligand transitions. The simulated data have a discrepancy in the total number of $\pi \rightarrow \pi^{*}$ transitions, although this may be an artifact of our fitting Gaussian distributions to each transition that obscures lower intensity bands. Analysis of the individual major peaks shows five for $1 \cdot \mathrm{THF}$, five for $\mathbf{2} \cdot \mathrm{THF}$, and six for 3.THF. Note that 2.THF is missing the experimental peak at $371 \mathrm{~nm}$. On the basis of these simulated spectra, we can directly attribute the color change with THF binding to loss of the intense LMCT band with $d z^{2}$ as the acceptor orbital. The extremely weak absorption at $\sim 640 \mathrm{~nm}$ seen in each of the simulated spectra corresponds to a different, less allowed LMCT band corresponding to donation into the half-filled $d x^{2}-y^{2}$ orbital. Interestingly, the experimental spectra of all THF adduct complexes show an increase of the lower energy band with increasing temperature. Therefore, it could also be a result of the equilibrium between four- and five-coordinate species since the loss of THF is entropically favored at higher temperature. However, variable temperature NMR spectra of 2.THF (Figure S7) exhibit one set of resonances, implying that either only $\mathbf{2} \cdot$ THF existed in the solution at these temperatures or the equilibrium is too rapid between 4- and 5coordinate complexes to be observed on the NMR time scale.

\section{Conclusions}


We have prepared and characterized a series of $\mathrm{Ni}(\mathrm{II})$ complexes supported by a monoanionic NNN pincer ligand, $\mathrm{Cz}^{\mathrm{tBu}}\left(\mathrm{Pyr}^{\mathrm{iPr}}\right)_{2}^{-}$. 1-3 were found to have $S=1$ configurations, which calculations suggest is due to the geometric constraints of the pincer ligand. The combined experimental and theoretical exploration of the electronic and geometric structure of these and related hypothetical complexes highlight an important feature of this new ligand (and related ones): unlike PNP and bis-iminopyridine ligands whose substituents point away from the fourth coordination site of the metal, ${ }^{13,71-72}$ the $\mathrm{R}$ groups of pyrazole directly conflict with a possible square planar geometry at $\mathrm{Ni}(\mathrm{II})$. This leads to a strong preference for the triplet state except when: (i) strong field ligands are used $\left(\mathrm{CN}^{-}\right.$is predicted to barely favor low-spin) or (ii) a ligand with no steric effect $\left(\mathrm{H}^{-}\right)$is bound to Ni. Practically, this suggests that when substrates of catalytic interest are bound to the metal a high-spin configuration should be expected. Experimental and theoretical studies of the electronic transitions for these complexes show the transitions are dominated by both $\pi \rightarrow \pi^{*}$ and LMCT bands. Further reactivity studies on the rare examples of steric hindranceenforced seesaw complexes 1-3 are ongoing, and results will be published in due course. ASSOCIATED CONTENT

Supporting Information. Additional X-ray crystallographic data, ${ }^{1} \mathrm{H}$ NMR spectra, UV-vis spectra for 1, 2, 3, 1.THF, 2.THF, and 3.THF, and computational results. This material is available free of charge via the Internet at http://pubs.acs.org.

\section{AUTHOR INFORMATION}

Corresponding Author

*Wei-Tsung Lee: wlee5@luc.edu

Author Contributions 
\# These authors contributed equally.

All authors have given approval to the final version of the manuscript.

Funding Sources

This work was supported by start-up funds (Loyola University Chicago). The X-ray diffractometers were funded by National Science Foundation through the Major Research Instrumentation Program under Grant No. CHE 1039689 (Illinois State University) and 1625543 (Purdue University).

Notes

The authors declare no competing financial interest.

\section{ACKNOWLEDGMENT}

This work was supported by start-up funds (Loyola University Chicago). The X-ray diffractometers were funded by National Science Foundation through the Major Research Instrumentation Program under Grants No. CHE 1039689 (Illinois State University) and CHE 1625543 (Purdue University). We thank Dr. Daniel J. McElheny (University of Illinois at Chicago) for acquiring VT-NMR spectra, and Illinois State University for access to their diffractometer (compound 2).

\section{REFERENCES}

1. Csok, Z.; Vechorkin, O.; Harkins, S. B.; Scopelliti, R.; Hu, X., Nickel Complexes of a Pincer $\mathrm{NN}_{2}$ Ligand: Multiple Carbon-Chloride Activation of $\mathrm{CH}_{2} \mathrm{Cl}_{2}$ and $\mathrm{CHCl}_{3}$ Leads to Selective Carbon-Carbon Bond Formation. J. Am. Chem. Soc. 2008, 130, 8156-8157.

2. Deng, Q.-H.; Wadepohl, H.; Gade, L. H., The Synthesis of a New Class of Chiral Pincer Ligands and Their Applications in Enantioselective Catalytic Fluorinations and the NozakiHiyama-Kishi Reaction. Chem. Eur. J. 2011, 17, 14922-14928. 
3. Patel, U. N.; Pandey, D. K.; Gonnade, R. G.; Punji, B., Synthesis of Quinoline-Based NNN-Pincer Nickel(II) Complexes: A Robust and Improved Catalyst System for C-H Bond Alkylation of Azoles with Alkyl Halides. Organometallics 2016, 35, 1785-1793.

4. Pérez García, P. M.; Ren, P.; Scopelliti, R.; Hu, X., Nickel-Catalyzed Direct Alkylation of Terminal Alkynes at Room Temperature: A Hemilabile Pincer Ligand Enhances Catalytic Activity. ACS Catal. 2015, 5, 1164-1171.

5. Ren, P.; Vechorkin, O.; Allmen, K. v.; Scopelliti, R.; Hu, X., A Structure-Activity Study of Ni-Catalyzed Alkyl-Alkyl Kumada Coupling. Improved Catalysts for Coupling of Secondary Alkyl Halides. J. Am. Chem. Soc. 2011, 133, 7084-7095.

6. Tao, J.-L.; Wang, Z.-X., Pincer-Nickel-Catalyzed Cross-Coupling of Aryl Sulfamates with Arylzinc Chlorides. Eur. J. Org. Chem. 2015, 6534-6540.

7. Wenz, J.; Rettenmeier, C. A.; Wadepohl, H.; Gade, L. H., Catalytic C-F Bond Activation of Geminal Difluorocyclopropanes by Nickel(I) Complexes via a Radical Mechanism. Chem. Commun. 2016, 52, 202-205.

8. Zhang, X.-Q.; Wang, Z.-X., Cross-Coupling of Aryltrimethylammonium Iodides with Arylzinc Reagents Catalyzed by Amido Pincer Nickel Complexes. J. Org. Chem. 2012, 77, 36583663.

9. $\quad$ Hao, Z.; Yang, N.; Gao, W.; Xin, L.; Luo, X.; Mu, Y., Nickel Complexes Bearing N,N,Ntridentate Quinolinyl Anilido-Imine Ligands: Synthesis, Characterization and Catalysis on Norbornene Addition Polymerization. J. Organomet. Chem. 2014, 749, 350-355.

10. Pinheiro, A. C.; Virgili, A. H.; Roisnel, T.; Kirillov, E.; Carpentier, J. F.; Casagrande, O. L., Ni(II) Complexes Bearing Pyrrolide-Imine Ligands with Pendant N-, O- and S-Donor Groups: Synthesis, Structural Characterization and Use in Ethylene Oligomerization. RSC Adv. 2015, 5, 91524-91531.

11. Filimon, S.-A.; Petrovic, D.; Volbeda, J.; Bannenberg, T.; Jones, P. G.; Freiherr von Richthofen, C.-G.; Glaser, T.; Tamm, M., $3 d$ Metal Complexes Supported by a Bis(imidazolin-2imino)pyridine Pincer Ligand - Synthesis, Structural Characterisation, and Magnetic Properties. Eur. J. Inorg. Chem. 2014, 5997-6012.

12. Peters, J. C.; Harkins, S. B.; Brown, S. D.; Day, M. W., Pincer-like Amido Complexes of Platinum, Palladium, and Nickel. Inorg. Chem. 2001, 40, 5083-5091.

13. Manuel, T. D.; Rohde, J.-U., Reaction of a Redox-Active Ligand Complex of Nickel with Dioxygen Probes Ligand-Radical Character. J. Am. Chem. Soc. 2009, 131, 15582-15583.

14. Huang, D.; Holm, R. H., Reactions of the Terminal Ni ${ }^{\mathrm{II}}-\mathrm{OH}$ Group in Substitution and Electrophilic Reactions with Carbon Dioxide and Other Substrates: Structural Definition of Binding Modes in an Intramolecular $\mathrm{Ni}^{\mathrm{II}}{ }^{\mathrm{N}} \mathrm{Fe}^{\mathrm{II}}$ Bridged Site. J. Am. Chem. Soc. 2010, 132, 46934701.

15. Cariou, R.; Dahcheh, F.; Graham, T. W.; Stephan, D. W., Mononuclear and Dinuclear Palladium and Nickel Complexes of Phosphinimine-Based Tridentate Ligands. Dalton Trans. 2011, 40, 4918-4925.

16. Singleton, J. T., The Uses of Pincer Complexes in Organic Synthesis. Tetrahedron 2003, 59, 1837-1857.

17. van der Boom, M. E.; Milstein, D., Cyclometalated Phosphine-Based Pincer Complexes: Mechanistic Insight in Catalysis, Coordination, and Bond Activation. Chem. Rev. 2003, 103, 17591792. 
18. Benito-Garagorri, D.; Kirchner, K., Modularly Designed Transition Metal PNP and PCP Pincer Complexes based on Aminophosphines: Synthesis and Catalytic Applications. Acc. Chem. Res. 2008, 41, 201-213.

19. Bauer, G.; Hu, X., Recent Developments of Iron Pincer Complexes for Catalytic Applications. Inorg. Chem. Front. 2016, 3, 741-765.

20. van Koten, G.; Milstein, D., Organometallic Pincer Chemistry. Springer-Verlag: Berlin, Heidelberg, 2013.

21. Housecroft, C. E.; Sharpe, A. G., Inorgnic Chemistry. 4th ed.; Pearson Education limited: Harlow, England, 2012; p 761-764.

22. Greenwood, N. N.; Earnshaw, A., Chemistry of the Elements. 2nd ed.; Butterworth Heinemann: Oxford, U.K., 1997; p 1156-1166.

23. Bruschi, M.; Tiberti, M.; Guerra, A.; De Gioia, L., Disclosure of Key Stereoelectronic Factors for Efficient $\mathrm{H}_{2}$ Binding and Cleavage in the Active Site of [NiFe]-Hydrogenases. J. Am. Chem. Soc. 2014, 136, 1803-1814.

24. Rettenmeier, C. A.; Wenz, J.; Wadepohl, H.; Gade, L. H., Activation of Aryl Halides by Nickel(I) Pincer Complexes: Reaction Pathways of Stoichiometric and Catalytic Dehalogenations. Inorg. Chem. 2016, 55, 8214-8224.

25. Rettenmeier, C.; Wadepohl, H.; Gade, L. H., Stereoselective Hydrodehalogenation via a Radical-Based Mechanism Involving T-Shaped Chiral Nickel(I) Pincer Complexes. Chem. Eur. J. 2014, 20, 9657-9665.

26. Konrad, F.; Lloret Fillol, J.; Rettenmeier, C.; Wadepohl, H.; Gade, L. H., Bis(oxazolinylmethyl) Derivatives of $\mathrm{C}_{4} \mathrm{H}_{4} \mathrm{E}$ Heterocycles $(\mathrm{E}=\mathrm{NH}, \mathrm{O}, \mathrm{S})$ as $\mathrm{C}_{2}$-Chiral Meridionally Coordinating Ligands for Nickel and Chromium. Eur. J. Inorg. Chem. 2009, 49504961.

27. Rettenmeier, C. A.; Wadepohl, H.; Gade, L. H., Electronic Structure and Reactivity of Nickel(I) Pincer Complexes: Their Aerobic Transformation to Peroxo Species and Site Selective C-H Oxygenation. Chem. Sci. 2016, 7, 3533-3542.

28. Rettenmeier, C. A.; Wadepohl, H.; Gade, L. H., Structural Characterization of a Hydroperoxo Nickel Complex and Its Autoxidation: Mechanism of Interconversion between Peroxo, Superoxo, and Hydroperoxo Species. Angew. Chem. Int. Ed. 2015, 54, 4880-4884.

29. Broring, M.; Prikhodovski, S.; Brandt, C. D., The First (Tripyrrinato)nickel(II) Complexes, TrpyNiX with $\mathrm{X}=\mathrm{Cl}$, Br, I: Synthesis, Structures and Solvent Coordination. J. Chem. Soc., Dalton Trans. 2002, 4213-4218.

30. Bröring, M.; Prikhodovski, S.; Brandt, C. D., Structural Diversity in Five-Coordinate Nickel(II) Complexes of the Tripyrrin Ligand. Inorg. Chim. Acta 2004, 357, 1733-1738.

31. Bröring, M.; Prikhodovski, S.; Brandt, C. D.; Cónsul Tejero, E., Pillars, Layers, Pores and Networks from Nickeltripyrrins: A Porphyrin Fragment as a Versatile Building Block for the Construction of Supramolecular Assemblies. Chem. Eur. J. 2007, 13, 396-406.

32. Trofimenko, S.; Calabrese, J. C.; Thompson, J. S., Novel Polypyrazolylborate Ligands: Coordination Control through 3-Substituents of the Pyrazole Ring. Inorg. Chem. 1987, 26, 15071514.

33. Gibson, V. C.; Spitzmesser, S. K.; White, A. J. P.; Williams, D. J., Synthesis and Reactivity of 1,8-bis(imino)carbazolide Complexes of Iron, Cobalt and Manganese. Dalton Trans. 2003, 2718-2727. 
34. Lin, H.-J.; Lutz, S.; O'Kane, C.; Zeller, M.; Chen, C.-H.; Al Assil, T.; Lee, W.-T., Synthesis and Characterization of an Iron Complex Bearing a Hemilabile NNN-Pincer for Catalytic Hydrosilylation of Organic Carbonyl Compounds. Dalton Trans. 2018, 47, 3243-3247.

35. Schubert, E. M., Utilizing the Evans Method with a Superconducting NMR Spectrometer in the Undergraduate Laboratory. J. Chem. Educ. 1992, 69, 62.

36. Reflux is needed for the preparation of the chloride derivative 1.

37. We could not obtain single crystals of pure 2.THF. However, a co-crystal with the dibromide $\mathrm{Cz}^{\mathrm{tBu}}\left(\mathrm{Pyr}^{\mathrm{iPr}}\right)_{2} \mathrm{NiBr}_{2}$ as its lithium salt, [2.THF] $\left[\mathrm{Cz}^{\mathrm{tBu}}\left(\mathrm{Pyr}^{\mathrm{iPr}}\right)_{2} \mathrm{NiBr}_{2}\right]\left[\mathrm{Li}(\mathrm{THF})_{4}\right]$, yielded crystals suitable for crystallographic analysis and is used for structural comparison.

38. Apex2 v2013.4-1, v2014.11, v2014.1-1, SAINT V8.34A, SAINT V8.30C. Bruker AXS Inc.: Madison(WI), USA, 2013/2014.

39. Blessing, R., An empirical correction for absorption anisotropy. Acta Crystallogr. Sect. A: Found. Crystallogr. 1995, 51, 33-38.

40. Hubschle, C. B.; Sheldrick, G. M.; Dittrich, B., ShelXle: A Qt Graphical User Interface for SHELXL. J. Appl. Crystallogr. 2011, 44, 1281-1284.

41. Sheldrick, G., SHELXT - Integrated Space-Group and Crystal-Structure Determination. Acta Crystallogr. Sect. A: Found. Crystallogr. 2015, 71, 3-8.

42. Sheldrick, G., A Short History of SHELX. Acta Crystallogr. Sect. A: Found. Crystallogr. 2008, 64, 112-122.

43. Stephens, P. J.; Devlin, F. J.; Chabalowski, C. F.; Frisch, M. J., Ab Initio Calculation of Vibrational Absorption and Circular Dichroism Spectra Using Density Functional Force Fields. $J$. Phys. Chem. 1994, 98, 11623-11627.

44. Becke, A. D., A New Mixing of Hartree-Fock and Local Density-Functional Theories. $J$. Chem. Phys. 1993, 98, 1372-1377.

45. Becke, A. D., Density-Functional Exchange-Energy Approximation with Correct Asymptotic Behavior. Phys. Rev. A 1988, 38, 3098-3100.

46. Lee, C.; Yang, W.; Parr, R. G., Development of the Colle-Salvetti Correlation-Energy Formula into a Functional of the Electron Density. Phys. Rev. B 1988, 37, 785-789.

47. Vosko, S. H.; Wilk, L.; Nusair, M., Accurate Spin-Dependent Electron Liquid Correlation Energies for Local Spin Density Calculations: A Critical Analysis. Can. J. Phys. 1980, 58, 12001211.

48. $\quad$ Frisch, M. J.; Trucks, G. W.; Schlegel, H. B.; Scuseria, G. E.; Robb, M. A.; Cheeseman, J. R.; Scalmani, G.; Barone, V.; Mennucci, B.; Petersson, G. A.; Nakatsuji, H.; Caricato, M.; Li, X.; Hratchian, H. P.; Izmaylov, A. F.; Bloino, J.; Zheng, G.; Sonnenberg, J. L.; Hada, M.; Ehara, M.; Toyota, K.; Fukuda, R.; Hasegawa, J.; Ishida, M.; Nakajima, T.; Honda, Y.; Kitao, O.; Nakai, H.; Vreven, T.; Montgomery, J. A.; Peralta, J., J. E.; Ogliaro, F.; Bearpark, M.; Heyd, J. J.; Brothers, E.; Kudin, K. N.; Staroverov, V. N.; Keith, T.; Kobayashi, R.; Normand, J.; Raghavachari, K.; Rendell, A.; Burant, J. C.; Lyengar, S. S.; Tomasi, J.; Cossi, M.; Rega, N.; Millam, J. M.; Klene, M.; Knox, J. E.; Cross, J. B.; Bakken, V.; Adamo, C.; Jaramillo, J.; Gomperts, R.; Stratmann, R. E.; Yazyev, O.; Austin, A. J.; Cammi, R.; Pomelli, C.; Ochterski, J. W.; Martin, R. L.; Morokuma, K.; Zakrzewski, V. G.; Voth, G. A.; Salvador, P.; Dannenberg, J. J.; Dapprich, S.; Daniels, A. D.; Farkas, O.; Foresman, J. B.; Ortiz, J. V.; Cioslowski, J.; Fox, D. J. Gaussian 09, Revision D.01, Gaussian, Inc.: Wallingford CT, 2010.

49. Schlegel, H. B., Geometry Optimization. Wiley Interdisciplinary Reviews: Computational Molecular Science 2011, 1, 790-809. 
50. Schlegel, H. B.; McDouall, J. J., Computational Advances in Organic Chemistry. Kluwer Academic: Amsterdam, The Netherlands, 1991.

51. Bauernschmitt, R.; Ahlrichs, R., Stability Analysis for Solutions of the Closed Shell KohnSham Equation. J. Chem. Phys. 1996, 104, 9047-9052.

52. Marenich, A. V.; Cramer, C. J.; Truhlar, D. G., Universal Solvation Model Based on Solute Electron Density and on a Continuum Model of the Solvent Defined by the Bulk Dielectric Constant and Atomic Surface Tensions. J. Phys. Chem. B 2009, 113, 6378-6396.

53. Weigend, F.; Ahlrichs, R., Balanced Basis Sets of Split Valence, Triple Zeta Valence and Quadruple Zeta Valence Quality for H to Rn: Design and Assessment of Accuracy. Phys. Chem. Chem. Phys. 2005, 7, 3297-3305.

54. Adamo, C.; Jacquemin, D., The Calculations of Excited-State Properties with TimeDependent Density Functional Theory. Chem. Soc. Rev. 2013, 42, 845-856.

55. Stratmann, R. E.; Scuseria, G. E.; Frisch, M. J., An Efficient Implementation of TimeDependent Density-Functional Theory for the Calculation of Excitation Energies of Large Molecules. J. Chem. Phys. 1998, 109, 8218-8224.

56. Dennington, R.; Keith, T.; Millam, J. GaussView, Version 5.0.9., Semichem Inc.: Shawnee Mission, KS, 2009.

57. Legault, C. Y. CYLview, 1.0b, Universite de Sherbrooke: 2009.

58. Johnson, K. R. D.; Kamenz, B. L.; Hayes, P. G., Bis(pyrazolyl)carbazole as a Versatile Ligand for Supporting Lutetium Alkyl and Hydride Complexes. Organometallics 2014, 33, 30053011.

59. Yang, L.; Powell, D. R.; Houser, R. P., Structural Variation in Copper(I) Complexes with Pyridylmethylamide Ligands: Structural Analysis with a New Four-Coordinate Geometry Index, ז. Dalton Trans. 2007, 955-964.

60. Reineke, M. H.; Sampson, M. D.; Rheingold, A. L.; Kubiak, C. P., Synthesis and Structural Studies of Nickel $(0)$ Tetracarbene Complexes with the Introduction of a New Four-Coordinate Geometric Index, $\tau \delta$. Inorg. Chem. 2015, 54, 3211-3217.

61. Perez Garcia, P. M.; Di Franco, T.; Epenoy, A.; Scopelliti, R.; Hu, X., From Dimethylamine to Pyrrolidine: The Development of an Improved Nickel Pincer Complex for Cross-Coupling of Nonactivated Secondary Alkyl Halides. ACS Catal. 2016, 6, 258-261.

62. Frampton, A. K.; Gartland, K.; Piro, N. A.; Kassel, W. S.; Dougherty, W. G., Structural Characterization and Electrochemical Properties of Nickel (II) Complexes Bearing Sterically Bulky Hydrotris(3-phenyl)- and Hydrotris(3-tert-butylpyrazol-1-yl)borato Ligands. Polyhedron 2016, 114, 172-178.

63. Migani, A.; Illas, F., A Systematic Study of the Structure and Bonding of Halogens on Low-Index Transition Metal Surfaces. J. Phys. Chem. B 2006, 110, 11894-11906.

64. Addison, A. W.; Rao, T. N.; Reedijk, J.; van Rijn, J.; Verschoor, G. C., Synthesis, Structure, and Spectroscopic Properties of Copper(II) Compounds Containing Nitrogen-Sulphur Donor Ligands; the Crystal and Molecular Structure of Aqua[1,7-bis(N-methylbenzimidazol-2'-yl)-2,6dithiaheptane]copper(II) Perchlorate. J. Chem. Soc., Dalton Trans. 1984, 1349-1356.

65. Chatt, J.; Kan, C. T.; Leigh, G. J.; Pickett, C. J.; Stanley, D. R., Transition-Metal Binding Sites and Ligand Parameters. J. Chem. Soc., Dalton Trans. 1980, 2032-2038.

66. Mukherjee, S.; Torres, D. E.; Jakubikova, E., HOMO Inversion as a Strategy for Improving the Light-Absorption Properties of Fe(II) Chromophores. Chem. Sci. 2017, 8, 8115-8126. 
67. Iweta, P. R.; Denise, Z.; Michael, P.; B., K. K.; Lutz, G.; Beatrice, B. C.; Stefan, H.; Christian, L., Comparing Isomeric Tridentate Carbazole-Based Click Ligands: Metal Complexes and Redox Chemistry. Chem. Eur. J. 2018, 24, 5341-5349.

68. Perdew, J. P.; Burke, K.; Ernzerhof, M., Generalized Gradient Approximation Made Simple. Phys. Rev. Lett. 1996, 77, 3865-3868.

69. Swart, M., Accurate Spin-State Energies for Iron Complexes. J. Chem. Theory Comput. 2008, 4, 2057-2066.

70. Handy, N. C.; Cohen, A. J., Left-right Correlation Energy. Mol. Phys. 2001, 99, 403-412.

71. Vogt, M.; Rivada-Wheelaghan, O.; Iron, M. A.; Leitus, G.; Diskin-Posner, Y.; Shimon, L. J. W.; Ben-David, Y.; Milstein, D., Anionic Nickel(II) Complexes with Doubly Deprotonated PNP Pincer-Type Ligands and Their Reactivity toward $\mathrm{CO}_{2}$. Organometallics 2013, 32, 300-308.

72. Adhikari, D.; Mossin, S.; Basuli, F.; Huffman, J. C.; Szilagyi, R. K.; Meyer, K.; Mindiola, D. J., Structural, Spectroscopic, and Theoretical Elucidation of a Redox-Active Pincer-Type Ancillary Applied in Catalysis. J. Am. Chem. Soc. 2008, 130, 3676-3682.

\section{SYNOPSIS}

A rigid NNN pincer ligand enforces a series of rare seesaw Ni(II) complexes. Upon dissolving the four-coordinate complexes in THF, the thermochromic five-coordinate THF adduct compounds were obtained.

TOC Picture

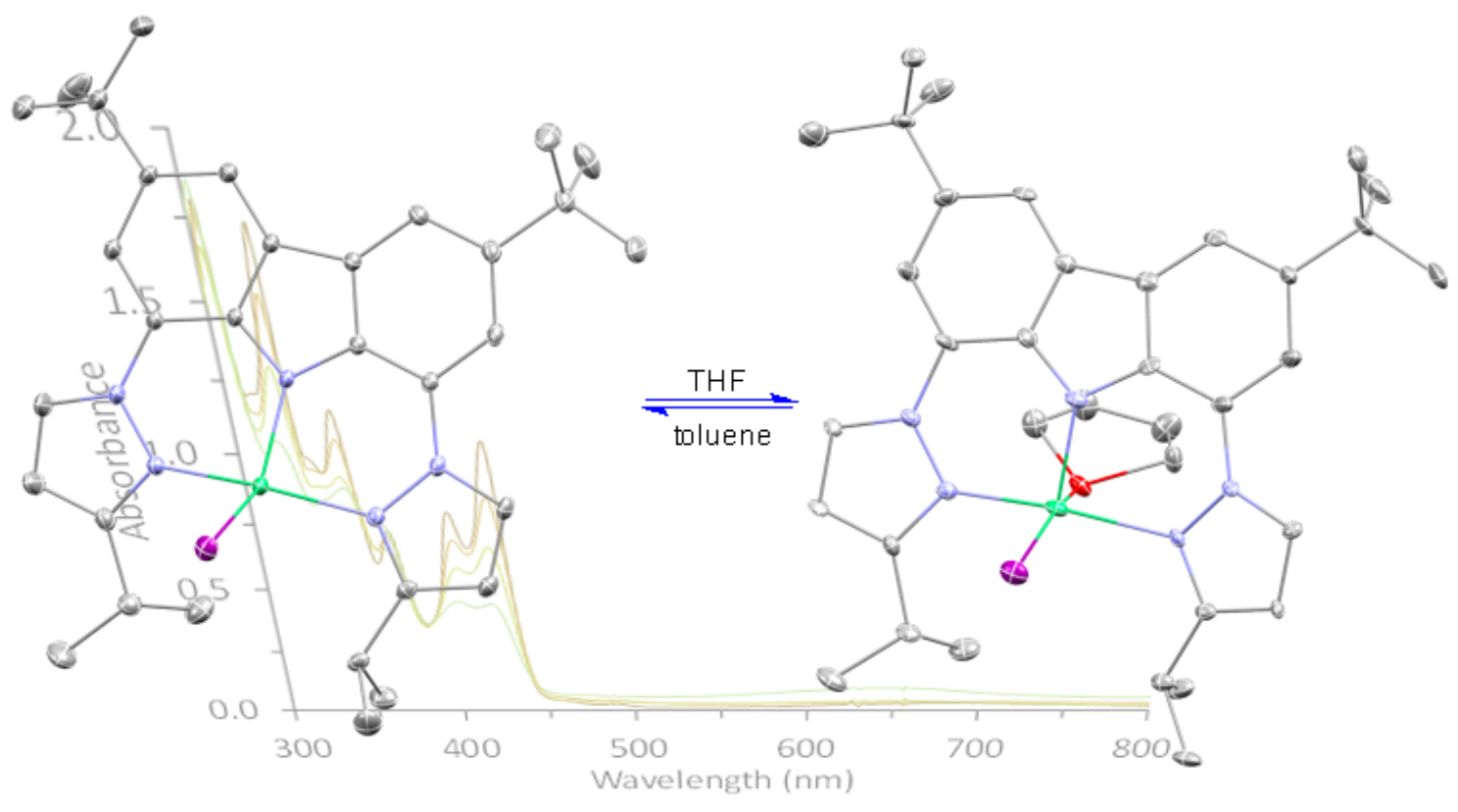

